\title{
Spectrum of immune checkpoint inhibitors- induced endocrinopathies in cancer patients: a scoping review of case reports
}

Meng H. Tan ${ }^{1 *}$ D, Ravi lyengar ${ }^{1,2}$, Kara Mizokami-Stout ${ }^{1}$, Sarah Yentz ${ }^{3}$, Mark P. MacEachern ${ }^{4}$, Li Yan Shen ${ }^{5}$, Bruce Redman ${ }^{3}$ and Roma Gianchandani ${ }^{1}$

\begin{abstract}
Background: Since 2011 six immune checkpoint inhibitors (ICl) have been approved to treat patients with many advanced solid tumor and hematological malignancies to improve their prognosis. Case reports of their endocrine immune-related adverse events [irAEs]) are increasingly published as more real-world patients with these malignancies are treated with these drugs. They alert physicians of a drug's AEs (which may change during a drug's life cycle) and contribute to post-marketing safety surveillance. Using a modified framework of Arksey and O'Malley, we conducted a scoping review of the spectrum and characteristics of ICl-induced endocrinopathies case reports before and after ICls are marketed.
\end{abstract}

Methods: In July 2017, we searched, without date and language restrictions, 4 citation databases for ICl-induced endocrinopathies. We also hand-searched articles' references, contents of relevant journals, and ran supplemental searches to capture recent reports through January 2018. For this study, a case should have information on type of cancer, type of ICl, clinical presentation, biochemical tests, treatment plus temporal association of ICl initiation with endocrinopathies. Two endocrinologists independently extracted the data which were then summarized and categorized.

Results: One hundred seventy nine articles reported 451 cases of ICl-induced endocrinopathies - 222 hypopituitarism, 152 thyroid disorders, 66 diabetes mellitus, 6 primary adrenal insufficiencies, 1 ACTH-dependent Cushing's syndrome, 1 hypoparathyroidism and 3 diabetes insipidus cases. Their clinical presentations reflect hormone excess or deficiency. Some were asymptomatic and others life-threatening. One or more endocrine glands could be affected. Polyglandular endocrinopathies could present simultaneously or in sequence. Many occur within 5 months of therapy initiation; a few occurred after ICI was stopped. Mostly irreversible, they required long-term hormone replacement. High dose steroids were used when non-endocrine AEs coexisted or as therapy in adrenal insufficiency. There was variability of information in the case reports but all met the study criteria to make a diagnosis.

Conclusions: The spectrum of ICl-induced endocrinopathies is wide ( 5 glands affected) and their presentation varied (12 endocrinopathies). Clinical reasoning integrating clinical, biochemical and treatment information is needed to properly diagnose and manage them. Physicians should be vigilant for their occurrence and be able to diagnose, investigate and manage them appropriately at onset and follow-up.

Keywords: Cancer immunotherapy, Immune checkpoint inhibitors (ICI), ICl-induced endocrinopathies, Endocrine immune-related AEs

\footnotetext{
* Correspondence: mengt@med.umich.edu

'Division of Metabolism, Endocrinology \& Diabetes, Department of Internal

Medicine, University of Michigan, 24 Frank Lloyd Wright Drive, Ann Arbor, Ml

48106, USA

Full list of author information is available at the end of the article
}

(c) The Author(s). 2019 Open Access This article is distributed under the terms of the Creative Commons Attribution 4.0 International License (http://creativecommons.org/licenses/by/4.0/), which permits unrestricted use, distribution, and reproduction in any medium, provided you give appropriate credit to the original author(s) and the source, provide a link to the Creative Commons license, and indicate if changes were made. The Creative Commons Public Domain Dedication waiver (http://creativecommons.org/publicdomain/zero/1.0/) applies to the data made available in this article, unless otherwise stated. 


\section{Introduction}

Advances in our understanding of the immune response to cancer and mechanisms of immune modulation have been translated to immunotherapy for the treatment of many advanced solid tumor and hematological malignancies. The two most promising advances in cancer immunotherapy are cell-based adoptive therapy modalities and immune regulatory modalities. The immune regulatory modalities currently have a wider therapeutic utility than cell-based therapies. They consist of monoclonal antibodies (mAbs) to proteins known as immune checkpoint regulators - cytotoxic T-lymphocyte-associated antigen-4 (CTLA-4), programmed cell death protein-1 (PD-1) and programmed death ligand 1 and 2 (PD-L1 and PD-L2) [1-6].

PD-1 and CTLA-4 are found on lymphocytes. PD-L1/ L2 are found on many cells, including tumor cells. The typical function of these checkpoint regulator proteins is to diminish the immune response to antigen, acting as a brake on the immune system [1-6]. Monoclonal Abs to these checkpoint regulator proteins, known as immune checkpoint inhibitors (ICIs), release the brake that has been placed on the immune system, allowing the patients' immune system to attack cancer cells and certain healthy tissues. There are currently 6 ICIs approved for the treatment of many advanced cancers (Table 1).

Use of ICIs brings forth a new toxicity called immunerelated Adverse Events (irAEs) whose mechanisms and manifestations are quite different from those of cytotoxic chemotherapy, radiation or molecularly targeted agents. These irAEs are inflammatory in nature with potential to affect multiple organ systems. While not occurring in all patients, they are believed to be an autoimmune response that results from the blocking of the normal immune regulatory pathways. Common ICI irAEs include colitis, hepatitis, pneumonitis, dermatitis and endocrinopathies.

While non-endocrine irAEs require cessation of immunotherapy and usually resolve with immunosuppressive therapy [1-6], endocrine irAEs, if managed appropriately, do not require cessation of ICIs and are, for the most part, irreversible and require long term management [7, 8]. Endocrinologists will often be consulted to co-manage these patients and should be familiar with these endocrine irAEs (called ICI-induced endocrinopathies in this paper).

A drug's AE profile may change during its life cycle. Marketed drugs may have previously unreported AEs in real world patients because these patients do not have to meet study entry criteria of clinical trials. In addition, marketed drugs may have rare AEs which surface when many more patients are treated with them. In the United States (US), AEs of marketed drugs are reported by healthcare providers, patients and others directly or indirectly to the Food and Drug Administration (FDA). Healthcare providers may also publish their patient's AEs as case reports in medical journals. Such publications contribute to post-marketing safety surveillance of drugs and alert clinicians to these possible drug AEs.

A 2016 systematic review of case reports of irAEs related to CTLA-4 and PD-1 blockade therapy [9] was based on a literature search done in August 2015, four years after the approval of anti-CTLA-4 mAB (ipilimumab) in 2011 and a few months after the approval of anti-PD-1 mAbs (nivolumab and pembrolizumab) in 2014. It included 84 cases of ICI-induced-endocrinopathies - 79 with ipilimumab, 2 with pembrolizumab and 3 with nivolumab.

Table 1 Immune checkpoint inhibitors approved by the Food and Drug Administration in USA

\begin{tabular}{|c|c|c|c|c|c|c|}
\hline & $\begin{array}{l}\text { Ipilimumab } \\
\text { CTLA-4 }\end{array}$ & $\begin{array}{l}\text { Nivolumab } \\
\text { PD-1 }\end{array}$ & $\begin{array}{l}\text { Pembrolizumab } \\
\text { PD-1 }\end{array}$ & $\begin{array}{l}\text { Atezolizumab } \\
\text { PD-L1 }\end{array}$ & $\begin{array}{l}\text { Avelumab } \\
\text { PD-L1 }\end{array}$ & $\begin{array}{l}\text { Durvalumab } \\
\text { PD-L1 }\end{array}$ \\
\hline \multicolumn{7}{|l|}{ Malignancy } \\
\hline Melanoma & $\sqrt{ } *(3 / 2011)$ & $\sqrt{ }^{*}(12 / 2014)$ & $\sqrt{ }^{*}(9 / 2014)$ & & & \\
\hline Non-small cell lung cancer & & $\sqrt{ }(3 / 2015)$ & $\sqrt{ }(10 / 2015)$ & $\sqrt{ }(10 / 2016)$ & & \\
\hline Renal cell carcinoma & & $\sqrt{ }(11 / 2015)$ & & & & \\
\hline Hepatocellular carcinoma & & $\sqrt{ }(9 / 2017)$ & & & & \\
\hline Classical Hodgkin's lymphoma & & $\sqrt{ }(5 / 2016)$ & $\sqrt{ }(3 / 2017)$ & & & \\
\hline Head \& neck squamous cell carcinoma4 & & $\sqrt{ }(11 / 2017)$ & $\sqrt{ }(8 / 2016)$ & & & \\
\hline Urothelial Carcinoma & & $\sqrt{ }(2 / 2017)$ & $\sqrt{ }(5 / 2017)$ & $\sqrt{*}(5 / 2016)$ & $\sqrt{ }(5 / 2017)$ & $\sqrt{ }^{*}(5 / 2017)$ \\
\hline Colorectal cancer with high msi/mrd & & $\sqrt{ }(8 / 2017)$ & & & & \\
\hline Gastric cancer & & & $\sqrt{ }(9 / 2017)$ & & & \\
\hline Solid tumor with high msi/mrd & & & $\sqrt{ }(7 / 2017)$ & & & \\
\hline Merkel-cell carcinoma & & & & & $\sqrt{ }^{*}(3 / 2017)$ & \\
\hline Bladder Cancer & & & & $\sqrt{ }(04 / 2017)$ & & \\
\hline
\end{tabular}

*First indication approval date by FDA 
Since that review [9], the profiles of ICI-induced endocrinopathies have changed for various reasons: (a) many more advanced cancer patients have been treated with ICIs; (b) the ICIs have been marketed longer; (c) more cancers have been approved for treatment with ICIs; (d) a new subclass of ICI drugs (anti PDL-1 mAbs) was approved in 2016/2017; and (e) rare cases of ICI-induced endocrinopathies have been reported as more patients are treated with these drugs.

In this paper, we report the findings of a scoping review of ICI-induced endocrinopathies case reports based on a literature search conducted in July 2017, 6 years after the approval of ipilimumab, 3 years after the approval of nivolumab and pembrolizumab, and about a year after the approval of atezolimumab, avelumab and durvalumab. We aim to uncover new knowledge of the changing profiles of ICI-induced endocrinopathies, before and after marketing, as more real-world patients with different advanced cancers are treated with these drugs.

\section{Method}

We used the framework proposed by Arksey and O'Malley [10] and modified by Levac et al. [11] to conduct this scoping review to map out the ICI-induced endocrinopathies.

\section{Stage 1: Identifying the research questions - Purpose}

What is the spectrum (extent, range and nature) of ICI-induced endocrinopathies? How and when did they present clinically? What investigations were conducted to support their diagnoses? How were they managed at onset and what were their outcomes?

\section{Stage 2: Identifying relevant studies- data sources and searches}

In July 2017, we searched 4 citation databases for published articles and abstracts of cases of endocrinopathies associated with ICI therapy for cancer. The search was initially developed in 3 Ovid MEDLINE databases (MEDLINE, In-Process \& Other Non-Indexed Citations, Epub Ahead of Print) and then optimized for Embase. com, Cochrane Central Register of Controlled Trials via Wiley Online Library, and Clarivate Analytics Web of Science. The searches were built with a combination of controlled terms (Medical Subject Headings and EMTREE when available), and title or abstracts keywords. No date or language restrictions were included in the searches, but animal studies, editorials, and comments were excluded from review.

Throughout the review process until January 31, 2018 the authors conducted hand-searches of reference lists in articles, reviewed the contents of relevant journals, and ran supplemental searches in Ovid MEDLINE, Embase, and the Cochrane Central Register to capture recently published reports. Duplicate citations were excluded in EndNote X6 (Clarivate Analytics). (All reproducible search strategies are available in Additional file 1: Appendix 1).

\section{Stage 3: Study selection}

For eligibility screening, the citations were categorized by type of endocrinopathy. For this review, a case should have information on the type of cancer, type of ICI used, clinical presentation, biochemical tests' results, imaging results (if done), and initial and follow-up treatment.

\section{Stage 4: Charting the data - Data extraction}

The citations were distributed to teams of at least 2 endocrinologists to review (pituitary, adrenal and parathyroid, and diabetes insipidus: MHT and LYS; thyroid: RI and MHT; Diabetes mellitus: KMS, RG and MHT). Using a 2-step approach, each team member reviewed the title and abstract to identify potentially eligible relevant citation. Then, the full paper, if available, was retrieved, reviewed and data extracted. Non-English articles were translated with Google Translate.

The reviewers screened all assigned citations independently using a standardized data extraction form (Additional file 2: Appendix 2) to collect data on each case according to the guidelines for AEs publication as recommended by the International Society of Pharmacoepidemiology and the International Society of Pharmacovigilance to evaluate the quality of case reports [12]. They then compared their decisions and resolved any differences by consensus.

Stage 5: Collating, summarizing and reporting the results For this review, a case should have information on the type of cancer, type of ICI used, clinical presentation, biochemical tests' results, imaging results (if done), and initial and follow-up treatment. When all the above is not reported, the case should have information on 2 of the following: clinical, biochemical and treatment information. To imply association, there should be close temporal relationship between ICI therapy initiation and subsequent development of endocrinopathy. We summarized and categorized the identified ICI-induced endocrinopathies according to the endocrine gland affected, whether it was associated with hyper- or hypofunction of the gland, and whether it involved one or more endocrinopathies (polyglandular endocrinopathies).

\section{Results}

Figure 1 shows the outcomes of the literature search. Of the 1041 citations identified, 218 had ICI-induced endocrinopathies citation with cases with sufficient information for this review. Some of these articles had information on two or more endocrinopathies. 


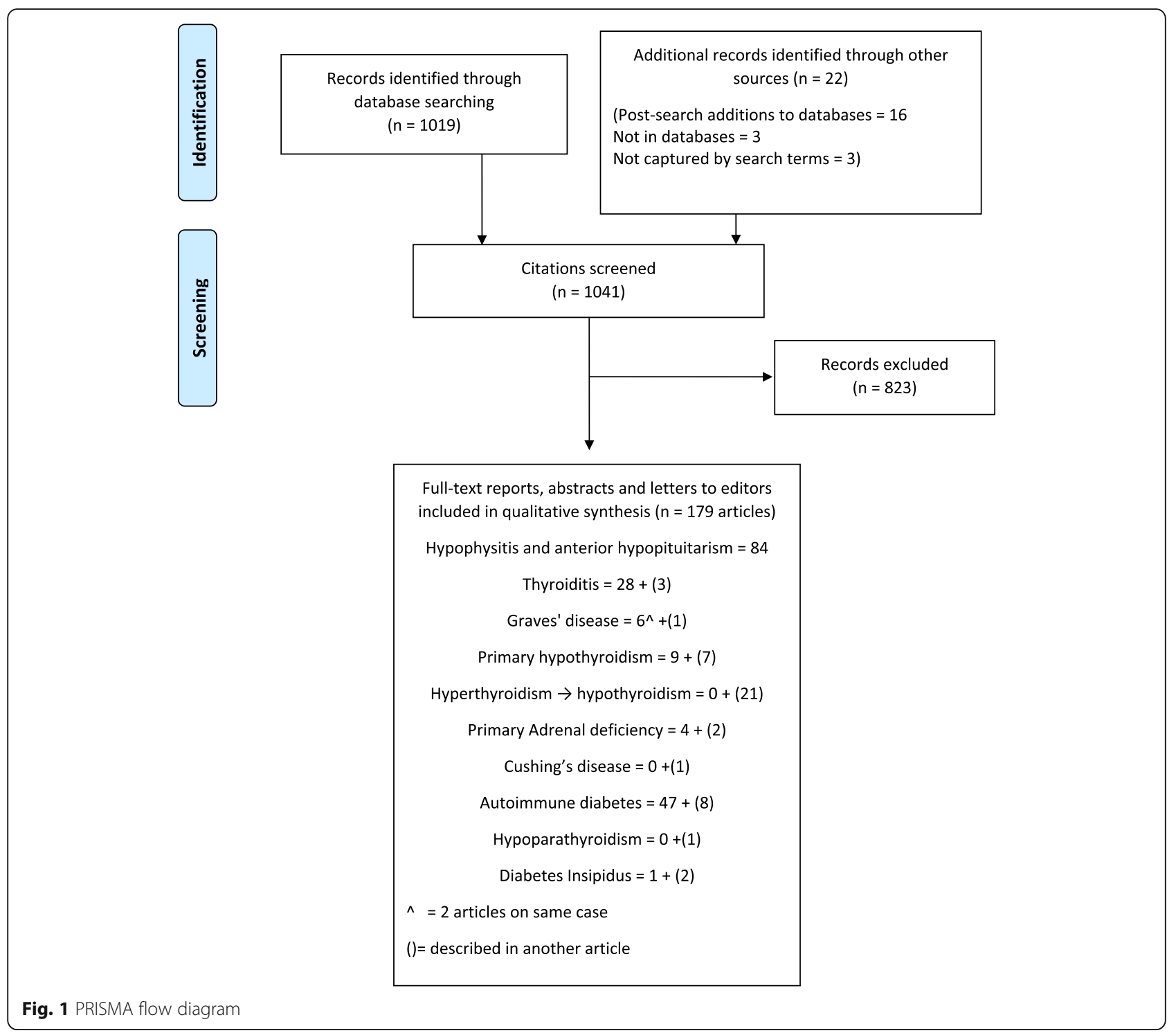

Eliminating these duplicates left 179 unique articles (116 papers, 43 abstracts and 20 letters to editor) which reported 451 cases of ICI-induced endocrinopathies that met study criteria for diagnosing the case.

Five endocrine glands are affected with 12 endocrinopathies:

- pituitary (hypopituitarism (multiple or isolated hormone deficiency[ies]), diabetes insipidus, and ACTH-dependent Cushing's syndrome);

- thyroid (thyrotoxicosis [Graves' disease and thyroiditis] and hypothyroidism [primary hypothyroidism and thyrotoxicosis progressing to hypothyroidism]),

- adrenal (primary adrenal insufficiency),

- pancreas (type 1 diabetes mellitus (T1DM) and type 2 diabetes mellitus (T2DM)), and

- parathyroid glands (primary hypoparathyroidism)

\section{Hypophysitis/anterior hypopituitarism}

Table 2 summarizes the data from the 222 cases of hypophysitis/anterior hypopituitarism [13-96]. (Details of each case are in Additional file 3: Appendix 3). Of the 222 cases, 220 met the inclusion criteria; the 2 without biochemical tests' results had clinical and treatment information.

This cohort's median age was 61 years. Most (65\%) were male (in contrast to mostly females in non-ICI induced autoimmune hypophysitis). The majority (87\%) had melanoma. CTLA-4 and PD-1/PD-L1 mAbs were used as monotherapy in 200 and 15 patients respectively with 7 on both. The median onset of clinical presentation was 12 weeks (range 3-76 weeks) after initiation of ICI. Symptoms reflected the associated hormone(s) deficiency(ies) with or without the mass-effect of pituitary enlargement (e.g. headache). In the 176 patients with 
Table 2 Cases of immune checkpoint inhibitors-induced hypophysitis and anterior pituitary insufficiency

\begin{tabular}{|c|c|}
\hline Variable & Information \\
\hline 1. Number of Reports & 84 \\
\hline 2. Cases & 222 \\
\hline 3. Gender & Males $=145 ;$ Females $=62 ;$ Not reported $=15$ \\
\hline 4. Age (years) & Median $=61 ;$ Mean $\pm S D=60.4 \pm 11.4 ;$ Range $=31-85$ \\
\hline 5. Pertinent medical history & $\begin{array}{l}\text { PHxEndoD: } \text { Reported }=12 ; \text { Not reported }=210 \\
\text { FHxEndoD: Reported }=2 ; \text { Not reported }=220 \\
\text { PHxAutoD: Reported }=4 ; \text { Not reported }=218\end{array}$ \\
\hline 6. Type of cancer & $\begin{array}{l}\text { Melanoma }=193 \text {; Renal cell carcinoma }=6 \text {; Prostate carcinoma }=7 \text {; non-small } \\
\text { cell lung cancer }=5 \text {, lung cancer }=5 \text {; papillary thyroid carcinoma }=1 ; \\
\text { mesothelioma }=1 \text {; not reported }=4\end{array}$ \\
\hline $\begin{array}{l}\text { 7. Check point inhibitor } \\
\text { ICI Drug D/C?: }\end{array}$ & $\begin{array}{l}\text { Ipilimumab = 188; Nivolumab }=13 ; \text { Tremelilumab }=4 ; \text { CTLA-4 = 8; Atezolizumab } \\
=2 ; \text { Ipilimumab }+ \text { Nivolumab }=3 ; \text { Nivolumab, then Ipilimumab = } 1 \text { I I ilimumab, } \\
\text { then Pembrolizumab }=2 ; \text { Ipilimumab, then Nivomumab }=1 . \\
\text { Yes }=45 \mathrm{No}=17 \text { Not reported }=160\end{array}$ \\
\hline 8. Clinical presentation & Reflects the hormone(s) affected \\
\hline 9. Onset (weeks) after first dose & Median $=12 ;$ Mean $=13.8 \pm 10.3 ;$ Range $3-76$ \\
\hline 10. Biochemical tests & $\begin{array}{l}\downarrow \text { ACTH/cortisol }=183 ; \\
\downarrow T S H / F T 4 / F T 3=172 ; \\
\downarrow L H / F S H / T / \text { Estradiol }=137 ; \\
\downarrow P R L=22 ; \downarrow G H / \text { IGF-1 = 22. } \uparrow T S H, \downarrow F T 4, / F T 3=2\end{array}$ \\
\hline 11. Diagnosis (patients with \# hormone deficiencies[def]) & $\begin{array}{l}5 \text { deficiency }(\text { def })=7 ; 4 \text { def }=14 ; 3 \text { def }=72 ; 2 \text { def }=47 ; \\
\text { One (isolated) def }=36(31 \mathrm{ACTH}, 4 \mathrm{TSH}, 1 \mathrm{LH}, \mathrm{FSH} \text { def). } \\
3 \text { reports with case series account for remainder }\end{array}$ \\
\hline 12. Imaging Brain/Pituitary MRI/CT & $\begin{array}{l}\text { Enlarged/Enhanced }=108 ; \text { Normal } 49 ; \text { Not reported }=11 \text {; Not done }=11 \text {; Sella } \\
\text { abnormality }=3 \text {; atrophy }=3 \\
3 \text { reports with case series account for remainder }\end{array}$ \\
\hline 13. CTCAE grade reported & Yes $=5 ;$ Not reported in 217 \\
\hline 14. Therapy at onset at diagnosis & High dose steroids $=144 ;$ steroids $=62 ;$ no steroids $=7 ;$ Not reported $=9$ \\
\hline 15. Outcome & 219 recovered/discharged (replacement therapy 195 \& 24 not reported); 3 deceased. \\
\hline
\end{tabular}

detailed hormone information, 36 had one hormone deficiency, 47 had two, 72 had three, 14 with four and 7 with five. Secondary adrenal deficiency was present in $83 \%$, secondary hypothyroidism in $77 \%$, and secondary hypogonadism in $53 \%$ of patients. Of the 167 patients with pituitary magnetic resonance imaging (MRI)/computerized tomography (CT) scans, 108 showed enlarged/ enhanced pituitary. Not all patients with enlarged pituitary presented with headaches and not all who presented with headaches $(n=126)$ had enlarged pituitary. High dose steroid was used as initial therapy in 69\%, physiological dose steroid in $29 \%$ and no steroid in $2 \%$ of patients. When the cases were published, 220 were alive and 2 diseased (cause of death not stated). Of the 220, 184 were on replacement therapy, 32 had no information on discharge medications, and 4 on no replacement medications. During the preapproval and post-marketing periods there were 18 and 204 (166 in the first 4 years of marketing) respectively. There were 9 cases of polyglandular endocrinopathies involving anterior hypopituitarism - plus thyroiditis [31, 45, 89], plus primary hypothyroidism [60, 82, 90, 93], plus Graves' disease and T1DM [76], and plus T1DM [95].

\section{Thyroid diseases}

Table 3 summarizes the data from the 152 cases of ICI-induced thyroid disorders (Details of each case [31, 60, 76, 80, 82, 90, 97-138] are in Additional file 4: Appendix 4).

\section{Thyrotoxicosis}

Of the 73 thyrotoxicosis cases, 6 had Graves' disease and 67 had thyroiditis. All had decreased thyroid stimulating hormone (TSH) and elevated free thyroxine (FT4)/free triiodothyronine (FT3) in addition to the clinical and treatment information. Those with Graves' disease also had positive thyrotropin receptor Ab (TRAb) or Thyroid Stimulating Immunoglobulin (TSI). Both groups may or may not have positive thyroid peroxidase (TPO) and/or thyroglobulin (TG) Ab. For those who had radioisotope thyroid scans, Graves' disease patients had increased uptake and thyroiditis patients had decreased uptake.

\section{Graves' disease}

This cohort's median age was 54.5 years. Four of the 6 patients were male. All had metastatic melanoma. Ipilimumab was used in 5/6 patients, 4 as monotherapy and 


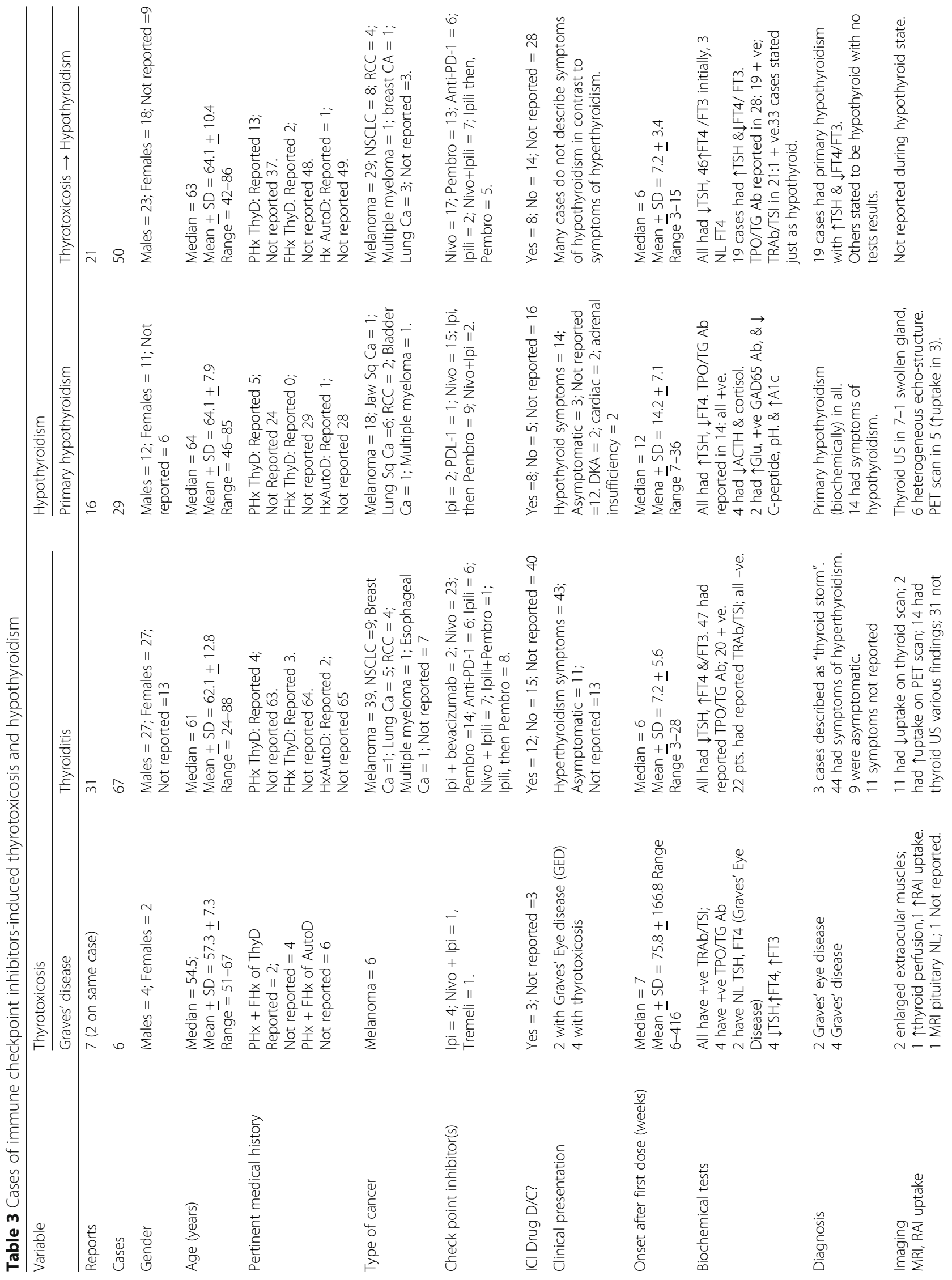


Tan et al. Clinical Diabetes and Endocrinology

(2019) 5:1

Page 7 of 21

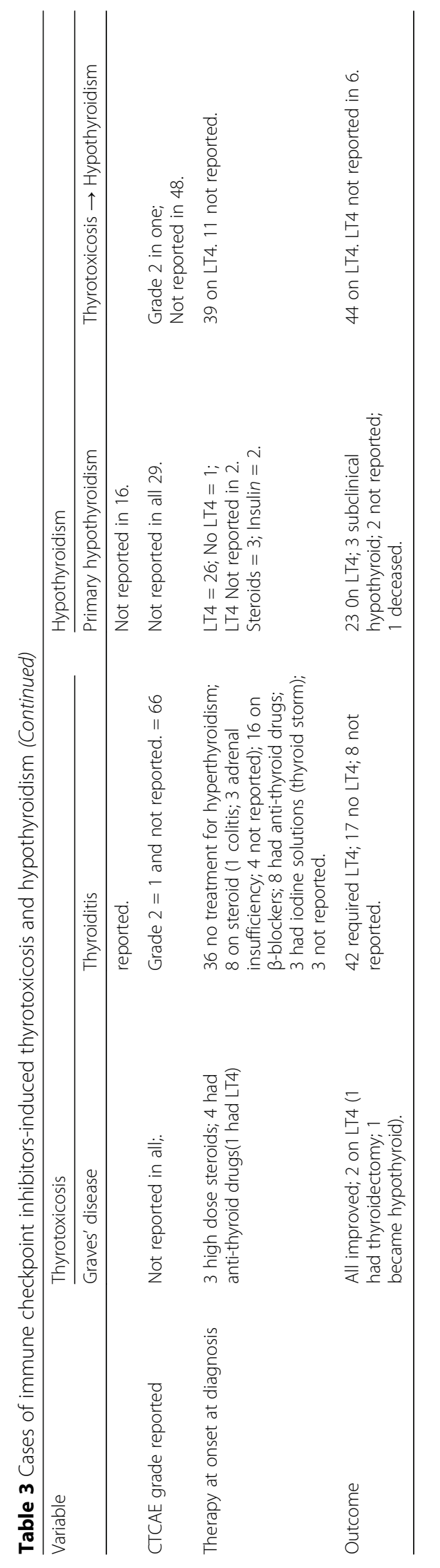


1 with Nivolumab. The median onset of clinical presentation was 7 weeks after initiation of ICI (range $=6-$ 416). Symptoms ranged from Graves' eye disease [97, 98] to hyperthyroidism. High dose steroid was used as initial therapy in 3 cases and anti-thyroid drugs in 4 cases. All improved and 2 were on replacement thyroxine (1 had thyroidectomy and the other became hypothyroid). Two cases were reported before ipilimumab approval and 3 post-marketing. One case used tremelimumab which has not been approved yet. One case of polyglandular endocrinopathy had Graves' disease followed by T1DM and anterior hypopituitarism [76].

\section{Thyroiditis}

This cohort's median age was 61 years. In those with identified gender, $53 \%$ were female. The majority (61\%) had metastatic melanoma. Anti-PD-1 mAbs were used in 60/67 patients, monotherapy in 44 and with/after Ipilimumab in 8 and 8 respectively. The median onset of symptoms was 6 weeks after initiation of ICI (range $=3-$ 28). Clinical presentation ranged from no symptoms to thyroid storm $[105,106,110]$. High dose steroid was used as initial therapy in 6 patients ( 2 of these cases had concomitant adrenal insufficiency), anti-thyroid drugs in 6 , $\beta$-blockers in 15 and iodide solution in 3. Of the 67 patients with follow-up information, 46 needed thyroxine replacement. During the pre-approval and post-marketing periods there were 2 and 65 reported respectively. There were 7 cases of polyglandular endocrinopathies involving thyroiditis - plus anterior hypopituitarism [31, 123, 126]; plus primary adrenal insufficiency [126]; plus pituitary adrenocorticotrophic hormone (ACTH)dependent Cushing's syndrome and anterior hypopituitarism [127]; plus hypoparathyroidism [122]; and plus type 1 diabetes mellitus $[128,130]$.

\section{Hypothyroidism}

Of the 79 cases of hypothyroidism, 29 had primary hypothyroidism and 50 had hypothyroidism preceded by transient hyperthyroidism. Primary hypothyroidism cases had elevated TSH and decreased FT4/FT3. In those with hyperthyroidism progressing to hypothyroidism, TSH (when reported) was high in 19 cases. The remaining 31 were stated to have hypothyroidism with clinical and/or treatment information.

\section{Primary hypothyroidism}

This cohort's median age was 64 years. In those with identified gender, $52 \%$ were male. Sixty-two percent had metastatic melanoma. As monotherapy anti-PD-1/PDL-1 mAbs were used in 16; with ipilimumab 11 (in sequence in 9 and combined 2) and ipilimumab monotherapy 2. The median onset of symptoms was 12 weeks after ICI initiation (range $=7-36$ ). Symptoms ranged from mild to severe myxedema coma [133]. Levothyroxine (LT4) was started in 26, no LT4 in 1 and 2 not reported. Steroids were used as initial therapy in 3 because of concomitant adrenal insufficiency and insulin was used in 2 to treat diabetes mellitus. In follow-up, 23 needed LT4 replacement, 5 not reported, and I died (cause unknown). During the pre-approval and post-marketing periods 1 and 28 cases were reported respectively. There were 6 cases of polyglandular endocrinopathies involving primary hypothyroidism - plus anterior hypopituitarism [60, 82, 90, 93] and plus diabetes mellitus [132, 134].

\section{Thyrotoxicosis progressing to hypothyroidism}

This cohort's median age was 63 years. In those with identified gender, $56 \%$ were male. The majority (59\%) had melanoma. Anti-PD-1/ PDL-1 mAbs were used in 48 patients - monotherapy in 36, after ipilimumab in 5 and in combination with ipilimumab in 7. The median onset of symptoms was 6 weeks after hyperthyroidism (range 3-15). Many patients were stated to be hypothyroid without clinical information on symptoms. At onset of symptoms 39 patients were prescribed LT4. In follow-up, 44 needed LT4 replacement, and LT4 replacement was not reported in 6 patients. All 50 cases were reported in post-marketing period. There were 7 cases of polyglandular endocrinopathies involving hyperthyroidism progressing to hypothyroidism - plus anterior hypopituitarism [76, 123];plus primary adrenal insufficiency (PAI) [126]; plus pituitary ACTH-dependent Cushing's syndrome [127]; plus hypoparathyroidism [122]; and plus T1DM [76, 128].

\section{Diabetes mellitus}

Table 4 summarizes the data from the 66 cases of ICI-induced diabetes mellitus. (Details of each case [76, 127, 128, 130, 139-185] are in Additional file 5: Appendix 5). All met the inclusion criteria.

Diagnosis of T1DM was based on clinical (onset, clinical symptoms, immediate and subsequent insulin therapy) and biochemical (glucose, ketone bodies, islet antibodies, acidotic state) data. Any case with positive islet antibody(ies) is diagnosed as T1DM based on the presumed underlying autoimmune nature. In cases where islet antibodies were negative or not reported, we diagnosed them to have T1DM based on their presentation with diabetic ketoacidosis (DKA) in a previously normoglycemic patient, new onset severe hyperglycemia with a low C-peptide in a patient without known diabetes, new insulin requirement in a patient with known T2DM; and anyone with "fulminant" T1DM.

This cohort's median age was 63 years. Most (64\%) were male and the majority (45\%) had metastatic 
Table 4 Cases of Immune Checkpoint Inhibitors Induced Diabetes Mellitus

\begin{tabular}{|c|c|}
\hline Variable & Information \\
\hline Reports & 55 \\
\hline Cases & 66 \\
\hline Gender & Males $=42 ;$ Females $=24$ \\
\hline Age (years) & Median $=63.5 ;$ Mean $\pm S D=62 \pm 13.2 ;$ Range $=28-84$ \\
\hline Pertinent medical history & $\begin{array}{l}\text { PHx diabetes: Reported = 36; Not reported }=30 \\
\text { FHx diabetes: Reported 27; Not reported }=39 \\
\text { Hx AutoD: Reported }=15 ; \text { Not reported }=51\end{array}$ \\
\hline Type of cancer (all metastatic) & $\begin{array}{l}\text { Melanoma }=30 ; \text { Non-small cell lung cancer }=10 \text {; Renal cell carcinoma }=7 ; \\
\text { Lung cancer }=11 ; \text { Urothelial carcinoma }=2, \text { Small cell jaw cancer }=1 \text {, Small } \\
\text { cell tonsillar cancer }=1 ; \text { Small cell maxillary sinus cancer }=1 ; \text { Hodgkin's } \\
\text { lymphoma }=1 \text {, Cholangiocarcinoma }=1 \text {, Not reported }=1\end{array}$ \\
\hline $\begin{array}{l}\text { Check point inhibitor } \\
\text { Drug } D / C ? \text { ? }\end{array}$ & $\begin{array}{l}\text { Pembro }=13 ; \text { Nivo }=32 ; \text { Nivo }+ \text { Ipi }=6 ; \text { Pembro }+ \text { Ipi }=1 ; \text { Ipi, then Pembro = } 5 \\
\text { Ipi, then Nivo }=3 ; \text { Avelu }+ \text { Utomi }=1 ; \text { Atezo }=2 ; \text { Unnamed PDL-1 }=2 ; \text { Ipi }=1 \\
\text { Yes }=22, \text { No }=15, \text { Ipi stopped } / \text { Pembro continued }=1 \text {, Not reported }=28\end{array}$ \\
\hline Clinical presentation & DKA $=43 ;$ Hyperglycemia $=20 ;$ Not reported $=3$ \\
\hline Onset (weeks) after first dose & Median $=7$, Mean $\pm S D=11.7 \pm 11.7$ Range $1-52$ \\
\hline Biochemical tests & $\begin{array}{l}\uparrow \text { Glucose }=57 ; \uparrow A 1 c=49 ; \uparrow \beta-\mathrm{OHB}=10 \\
\downarrow p H=35 ; \downarrow C-\text { pep }=48\end{array}$ \\
\hline Antibody evaluation & $\begin{array}{l}\text { Any antibodies (GAD65, IA2, ZnT8, IAA) positive = } 34 \text { (51.5\%) } \\
\text { Antibodies negative }=27(41 \%) \\
\text { Antibodies not reported }=5(7.5 \%)\end{array}$ \\
\hline Pancreatic imaging & $\begin{array}{l}\text { CT with } \downarrow \text { volume or atrophy }=3 \text {, CT with pancreatitis }=1 \text {; MRI with diffuse } \\
\text { inflammation }=1\end{array}$ \\
\hline CTCAE severity grade reported & Yes $=4$; Not reported $=62$ \\
\hline Therapy at onset at diagnosis in addition to insulin & Metformin $=1$, Glimepiride $=1$, glyburide $=1$; Diet $=2$, High dose steroids $*=10$ \\
\hline Outcome & $\begin{array}{l}\text { Remained insulin-dependent }=52 \text {, Recovered }=1 \text {, } \\
\text { Not reported }=13\end{array}$ \\
\hline
\end{tabular}

*Treatment dose steroids as part of chemotherapy regimen $(n=2)$, treatment of other autoimmune manifestation ( $n=3)$, to reverse autoimmune diabetes ( $=$ $2)$, to decrease insulin resistance $(n=1)$; for adrenal insufficiency $(n=2)$

melanoma. The ICIs used were anti-PD-I mAbs $(n=$ 45); anti-PD-L1 mAbs $(n=5)$; anti- PD-1 mAbs + anti-CTLA-4 mAb $(n=7)$; anti-CTLA-4 mAb then Anti-PD-1 mAbs $(n=8)$; anti CTLA- 4 mAb $(n=1)$. The median onset of clinical presentation was 7.5 weeks after initiation of ICI (range $=1-52$ weeks). Sixty-five had T1DM based on our diagnostic criteria (see above) and one probably had T2DM (had duodenopancreatectomy and did not require insulin to treat mild hyperglycemia) [178]. There were 4 cases with T2DM before ICI therapy and who developed T1DM based on a new insulin requirement when on ICI [132, 149, 171].

In the T1DM cohort, 43 presented in DKA and 20 with marked hyperglycemia. In the DKA group 12, mostly from Japan, were described to have fulminant T1DM [130, 139, 147, 148, 152-157, 165, 168-170]. Islet-related Abs (Glutamic acid decarboxylase 65(GAD 65), Islet Antigen 2 (IA2), Insulin auto-antibody (IAA) or Zinc Transporter 8 (ZnT8) Ab were positive in 51.5\% $(n=34)$, negative in $41 \%(n=27)$ and not reported in $7.5 \%(n=5)$. At onset of clinical presentation, high dose steroid was used in 10 , cases, insulin infusion in 60 , oral glucose-lowering medications initially continued in 4 , with 2 no information on treatment. All 66 patients recovered from their hyperglycemia with treatment - 53 remained insulin dependent and the outcomes of 13 were not reported. One patient, initially requiring insulin, discontinued insulin on day 81 after pembrolizumab was discontinued [142]. All the cases using anti-PD-1 mAbs were reported post-marketing, most 2-3 years after their approval in 2014. There were 6 cases of polyglandular endocrinopathies involving T1DM - plus anterior hypopituitarism [75, 95], plus anterior hypopituitarism + Graves' disease [76], plus, thyroiditis [129, 130], plus primary hypothyroidism [132], and plus hyperthyroidism progressing to hypothyroidism $[76,130]$.

Primary adrenal insufficiency, ACTH-dependent Cushing's syndrome, hypoparathyroidism, and diabetes insipidus

Table 5 summarizes the data from 6 cases of PAI, 1 of pituitary ACTH-dependent Cushing's syndrome, 1 of primary hypoparathyroidism and 3 of diabetes insipidus following ICI therapy. (Details of cases [16, 19, 34, 41, 122, 126, 127, 186-189] are in Additional file 6: Appendix 6). All met the criteria for inclusion in this review. 


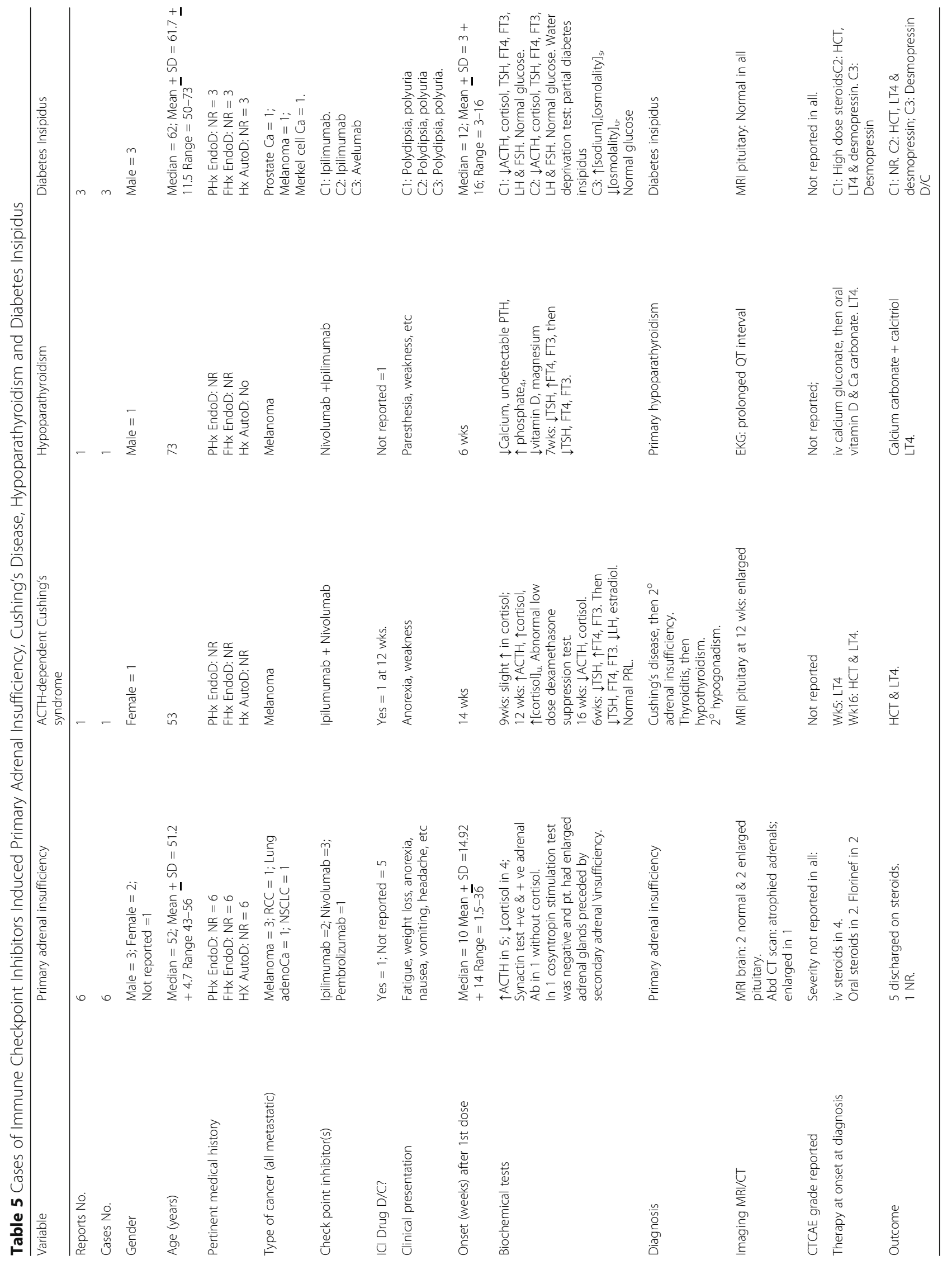




\section{Primary adrenal insufficiency [16, 34, 126, 186-188]}

This cohort's median age was 52 years. In those with identified gender, $60 \%$ were male. Of the 6 patients, 3 had metastatic melanoma. Anti-PD-1 mAbs were used in $4 / 6$ patients as monotherapy. Ipilimumab was used in 2 patients. The median onset of symptoms was 10 weeks after ICI initiation (range $=1.5-36$ ). High dose steroid was used as initial therapy in 4 and physiological steroids in 2 cases. All recovered clinically with treatment and were on replacement oral hydrocortisone with two [126, 186] also on fludrocortisone. The patient reported in [188] received iv prednisolone which contains some mineralocorticoid effect but at discharge fludrocortisones was not mentioned. One case [34] initially had secondary adrenal insufficiency (SAI) but was found to have enlarged adrenals at week 16 after ipilimumab initiation. When a cosyntropin stimulation test done then showed no cortisol response the authors concluded the patient also had PAI. A negative CST occurs in PAI but can also occur with SAI of significant duration.

\section{Pituitary ACTH-dependent Cushing's syndrome [127]}

Onset of the hypercortisolism symptoms was 12 weeks after initiation of ipilimumab plus nivolumab for melanoma. Four weeks later, secondary adrenal insufficiency developed. Both these were preceded by transient hyperthyroidism in week 6 that progressed to secondary hypothyroidism in week 9 after the first dose of ICI.

\section{Primary hypoparathyroidism [122]}

This melanoma patient, treated with ipilimumab plus nivolumab, developed symptoms of acute hypocalcemia 6 weeks after the first dose of ICIs. On the 3rd day in hospital, he developed transient thyroiditis which progressed to hypothyroidism.

\section{Diabetes insipidus (DI) [19, 41, 189]}

Two patients were treated with ipilimumab and 1 with avelumab (the first case of DI following anti-PD-L1 therapy). The median onset of symptoms (polydipsia and polyuria with euglycemia) was 12 weeks after initiation of ICI. Two [41, 189] reported biochemical data in keeping with DI and these 2 were discharged on desmopressin.

\section{Reported endocrinopathies not supported by data}

Two cases of hyponatremia were attributed to syndrome of inappropriate ADH secretion [22, 186]. However, both had secondary adrenal insufficiency that could have caused the hyponatremia.

The only case of hypercalcemia was associated with increased PTH-related peptide, not PTH; hence, it was not primary hyperparathyroidism [189].

\section{Discussion}

\section{Clinical presentations}

Compared with the 2016 systematic review of case reports of irAEs, which included 84 cases of endocrine irAEs, in ICI treated cancer patients [9], our review shows a five-fold increase in case reports of endocrine irAEs (from 84 to 451 ). This increase most likely reflects wider use of ICI therapy in more cancer patients - (a) more melanoma patients (the original indication) are now treated with 2 classes of ICIs; (b) as new indications are approved for other cancers, more patients are now treated with ICIs (Table 1); and (c) more cases of anti-PD-1-induced endocrinopathies were reported in the past 3 years after their approval in 2014 (Fig. 2). During the 3-4-years period after approval of each class of ICI (ipilimumab in 2011 and nivolumab and pembrolizumab in 2014) a striking increase in cases of ICI-induced endocrinopathies were published with their use in the first 2-3 years post-marketing period (Fig. 2). With the introduction of anti-PD-L1 drugs in 2016 and 2017 for cancer patients, more cases ICI-induced endocrinopathies [190] will likely be reported in the coming 3-4 years.

In the 2016 review [9] ipilimumab was associated with 68 cases of hypophysitis, 4 cases of thyrotoxicosis, 4 cases of hypothyroidism, 1 case of syndrome of inappropriate secretion of antidiuretic hormone, 1 case of central adrenal insufficiency, 1 case of primary adrenal insufficiency; pembrolizumab was associated with 1 case of hypothyroidism and 1 case of diabetes mellitus; and nivolumab was associated with 2 cases of hypothyroidism. Our scoping study uncovers a wider spectrum of ICI-induced endocrinopathies - 222 hypopituitarism, 152 thyroid disorders, 66 diabetes mellitus, 6 primary adrenal insufficiency, 1 pituitary ACTH-dependent Cushing's syndrome, 1 hypoparathyroidism and 3 diabetes insipidus cases (Fig. 3).

Clinically, endocrinopathies can present with symptoms of hormone deficiency, hormone excess or both (in the same or different glands). The spectrum of clinical presentation ranges from no symptoms [93, 111, 112, 116, 118, 135] (diagnosis made by biochemical tests) to severe, life-threatening symptoms - thyroid storm [105], myxedema coma [133] and diabetic ketoacidosis [144]. When symptomatic, the presentations of these ICI-induced endocrinopathies reflect the perturbations of hormone(s) produced by the affected gland(s).

Single hormone deficiency - ACTH in isolated ACTH deficiency $[34,45,70,86]$ or insulin in T1DM $[132,139$, $140,142])$ are more commonly reported than single hormone excess - thyroxine in Graves' disease [102] and ACTH in Cushing's syndrome [127]. Occasionally, the endocrinopathy may present with symptoms of one hormone excess followed by symptoms that reflect the same hormone's deficiency - hyperthyroidism progressing to hypothyroidism [116]. 


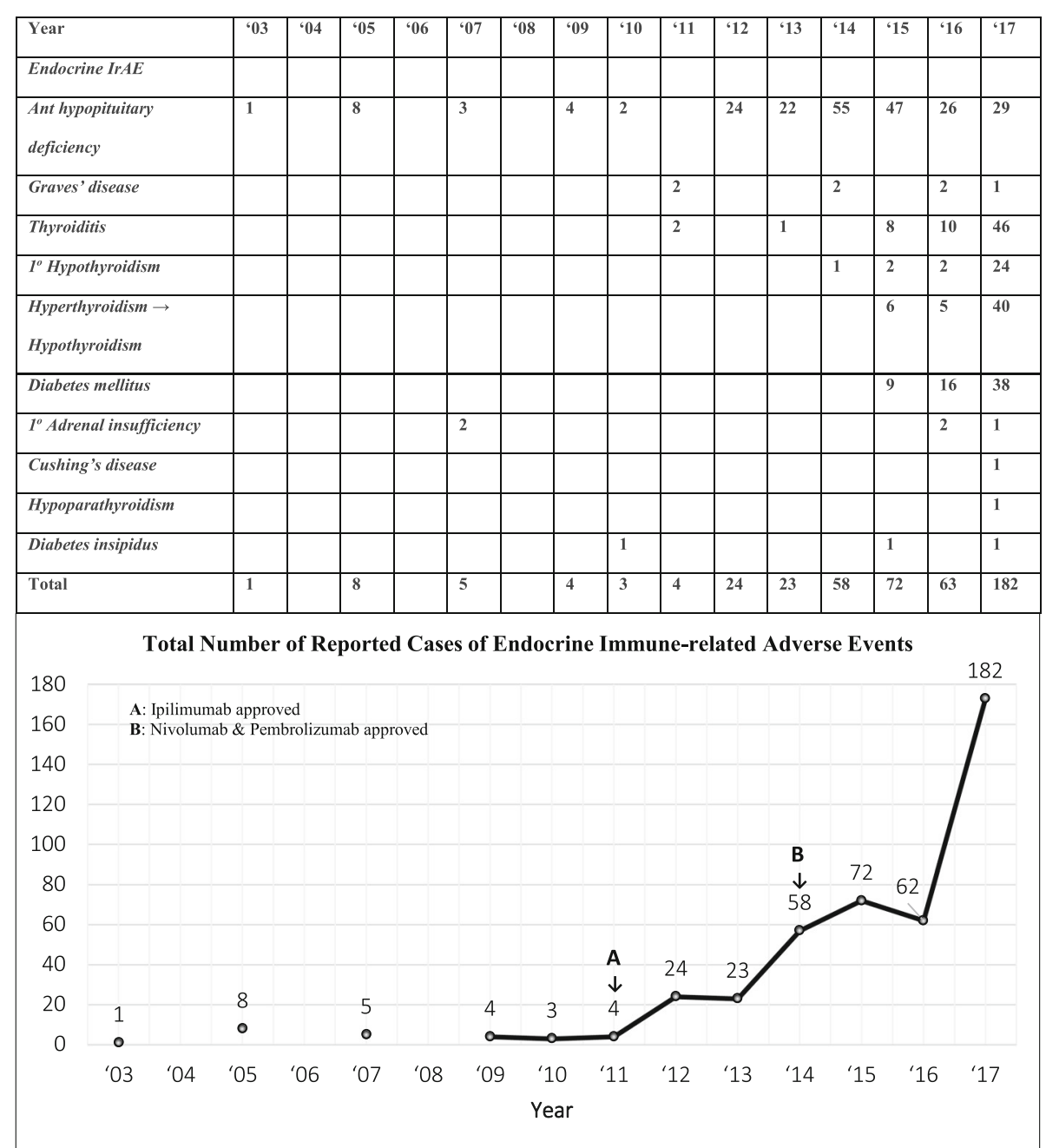

Fig. 2 Reported cases of immune checkpoint inhibitor-induced endocrinopathies are increasing

Multiple glands may be affected presenting as polyglandular endocrinopathies. The patient can present with symptoms and biochemical changes of two endocrine glands in sequence - thyroiditis and type 1 diabetes mellitus [130], hypoparathyroidism and thyroiditis [122], thyroiditis and ACTH-dependent Cushing's syndrome [127], and primary hypothyroidism and isolated ACTH deficiency [93].

When the pituitary gland, which secretes 7 hormones, is affected, multiple hormonal deficiencies can occur simultaneously; then, the patient presents with symptoms of multiple pituitary hormones deficiencies [14]. In our review, various combinations of pituitary hormone deficiencies occurred, with 3 hormone deficiencies being the commonest. Finally, patients with hypophysitis are sick and their thyroid/gonadal axis may be suppressed in the acute phase of the disease.

Onset of symptoms can occur as early as 1 week [140] or as late as 416 weeks [102] with most in the first 20 weeks.
The pituitary ACTH-dependent Cushing's syndrome [127] is the first case reported and needs to be confirmed. The etiology of the increased ACTH secretion may be due to ectopic Corticotropin-Releasing Hormone $(\mathrm{CRH})$ production as expression of $\mathrm{CRH}$ has been reported in advanced melanoma cells [191] and Cushing's syndrome due to ectopic CRH secretion has been reported [192]. As this case report's authors did not investigate this, we cannot comment further but raised this as a possible etiology and point out that this patient's Cushing's syndrome and hypophysitis are unlikely to be related. Whether and how the ICIs stimulate the secretion of $\mathrm{CRH}$ remains to be reported.

High-dose systemic glucocorticoids are given as immunosuppressive to treat concomitant non-endocrine irABs (colitis, hepatitis, etc). For endocrine irABs, high-dose systemic glucocorticoids are given to treat adrenal crisis, hypophysitis and in selected cases of thyroiditis. Such treatment did not improve the outcome of 


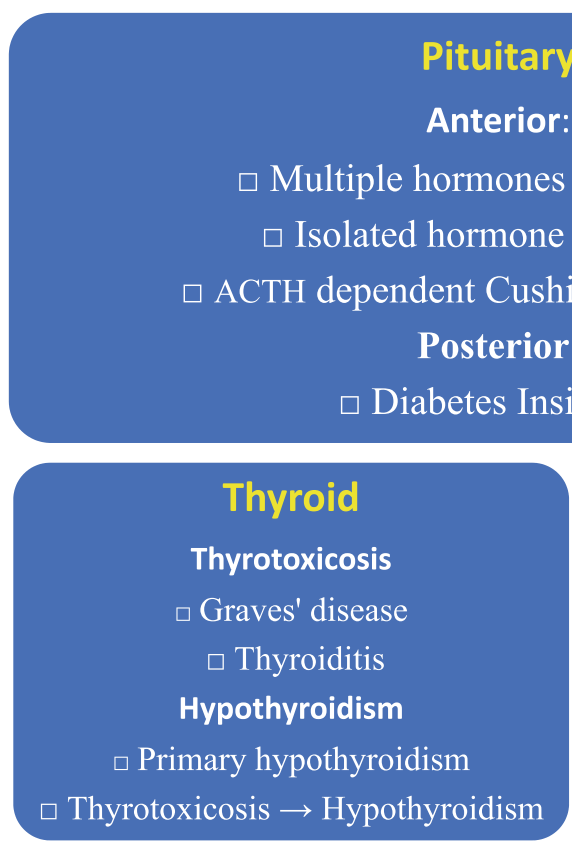

Pancreas

$\square$ Type 1 diabetes

$\square$ Type 2 diabetes

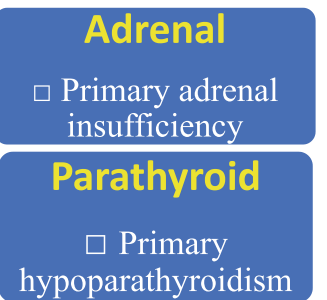

Fig. 3 Spectrum of immune checkpoint inhibitor-induced endocrinopathies

ipilimumab-related hypophysitis in melanoma patients [8]. Recently, high-dose glucocorticoids treatment for ipilimumab-related hypophysitis in melanoma patients was associated with reduced survival [193]. High dose systemic glucocorticoids when given to diabetes patients (see Table 4) can worsen their hyperglycemia.

\section{Subclass of $\mathrm{ICl}$ and $\mathrm{ICl}$-induced endocrinopathies}

We found anti-CTLA-4 mAb to be the ICI most frequently associated with hypophysitis and anterior pituitary hormone(s) deficiencies ( $n=188$ as monotherapy) compared with Anti-PD-1 mAbs $(n=13)$. The differences observed above may reflect longer period of use as ipilimumab was approved in 2011, 3 years before nivolumab and pembrolizumab. Other reasons, including biology of endocrine glands, may explain this difference (see below).

We found anti-PD-1 mAbs are the ICIs more often associated (when compared with CTLA-4 Ab) with autoimmune thyroiditis (37 vs 6 as monotherapy), primary hypothyroidism (15 vs 2 as monotherapy), hyperthyroidism progressing to hypothyroidism (30 vs 2 as monotherapy) and type 1 diabetes mellitus (45 vs 1 as monotherapy). Of note, in our review, all 6 patients with Graves' disease were treated with anti-CTLA-4 mAb (5 as monotherapy). A meta-analysis reported polymorphism of
CTLA-4 can increase the risk for Graves' disease [194] but how this interacts with ICI is unclear.

It is improper to calculate the frequency of each ICI-induced endocrinopathies in this review as we do not have the total number of cases that have been reported other than those that have been published. Cukier et al. reported frequencies of endocrine irAEs observed with immunotherapies [195]. Relevant to this review, the frequencies for endocrine irAEs for ipilimumab, nivolumab and pembrolizumab respectively are: hypophysitis $1.5-17$, $0.6-1.5$ and $0.6-1 \%$; hypothyroidism $1.5-6.8,9-10.8$ and 7-9.1\%; hyperthyroidism 4, 2.7 and 3.4-7.8\%; primary adrenal insufficiency $0.8-1.6,1 \%$ and not reported; Type 1 diabetes not reported, 0.9 , and $0.2 \%$. There are similarities in the frequencies of endocrinopathies associated with different ICIs reported by Cukier et al. [195] and those reported in this review.

\section{Pathogenesis}

How ICIs damage endocrine glands are unclear; however, several hypotheses to explain this have emerged [196]. All endocrinopathies associated with ICI therapy are hypothesized to be autoimmune in etiology. Checkpoint regulator proteins diminish the immune response to antigen and hence act as a brake on the immune system [1-6]. Blockade of these checkpoint regulator proteins releases this brake and allows the patient's immune 
system to attack cancer cells as well as damage certain healthy tissues by autoimmune mechanisms (Fig. 4).

For hypophysitis, a mouse model of anti-CLTA-4-induced hypophysitis demonstrated that CTLA-4 is expressed in pituitary endocrine cells and, when blocked by administration of anti-CTLA-4 mAb, leads to site-specific deposition of complement components, pituitary infiltration and pituitary $\mathrm{Ab}$ formation. This study also evaluated patients with prostate cancer and melanoma treated with ipilimumab and showed that those who developed hypophysitis developed pituitary Abs that were not seen in the patients who did not develop hypophysitis [47]. CTLA-4 antigen expressed by pituitary endocrine glands in cancer patients treated with CTLA-4 blockade was also reported by Caturegli et al. [63].

Hypophysitis is less common among patients treated with anti-PD-1/PD-L1 drugs. Some have hypothesized this is because mAbs to nivolumab and pembrolizumab are in the immunoglobulin (IgG) 4 class [197], as opposed to ipilimumab, a CTLA-4 antibody of the IgG1 class, which can activate the classical complement pathway [47].
The mechanism behind anti-PD-1 induced thyroid dysfunction is unclear. However, the development of anti-thyroid antibodies after the initiation of anti-PD-1 therapy suggests these drugs may be modulating the autoimmune equilibrium and unmasking latent autoimmunity [119]. As many cases of ICI-induced hypothyroidism are preceded by a period of transient hyperthyroidism, the mechanism may be destructive thyroiditis with release of thyroid antigen and consequent secondary antibody production [111]. In our study's thyroiditis cohort, of the 49 patients tested for TPO/TG $\mathrm{Ab}$, only 18 had positive titers. In addition, in one patient the hypothyroidism was preceded by Graves's disease [76].

In our study, in those autoimmune diabetes patients who were tested for islet-related Abs (GAD65, IA2, ZnT8, IAA) $51.5 \%$ had positive titers, $41 \%$ had negative titers and 7.5\% not reported. Insulin deficiency with low C-peptide was noted in over $70 \%$ patients. Several case reports [130, 147, 148, 152, 176, 177] of autoimmune diabetes following ICI therapy reported the HLA type of their patients increased their risk for developing type 1 diabetes.

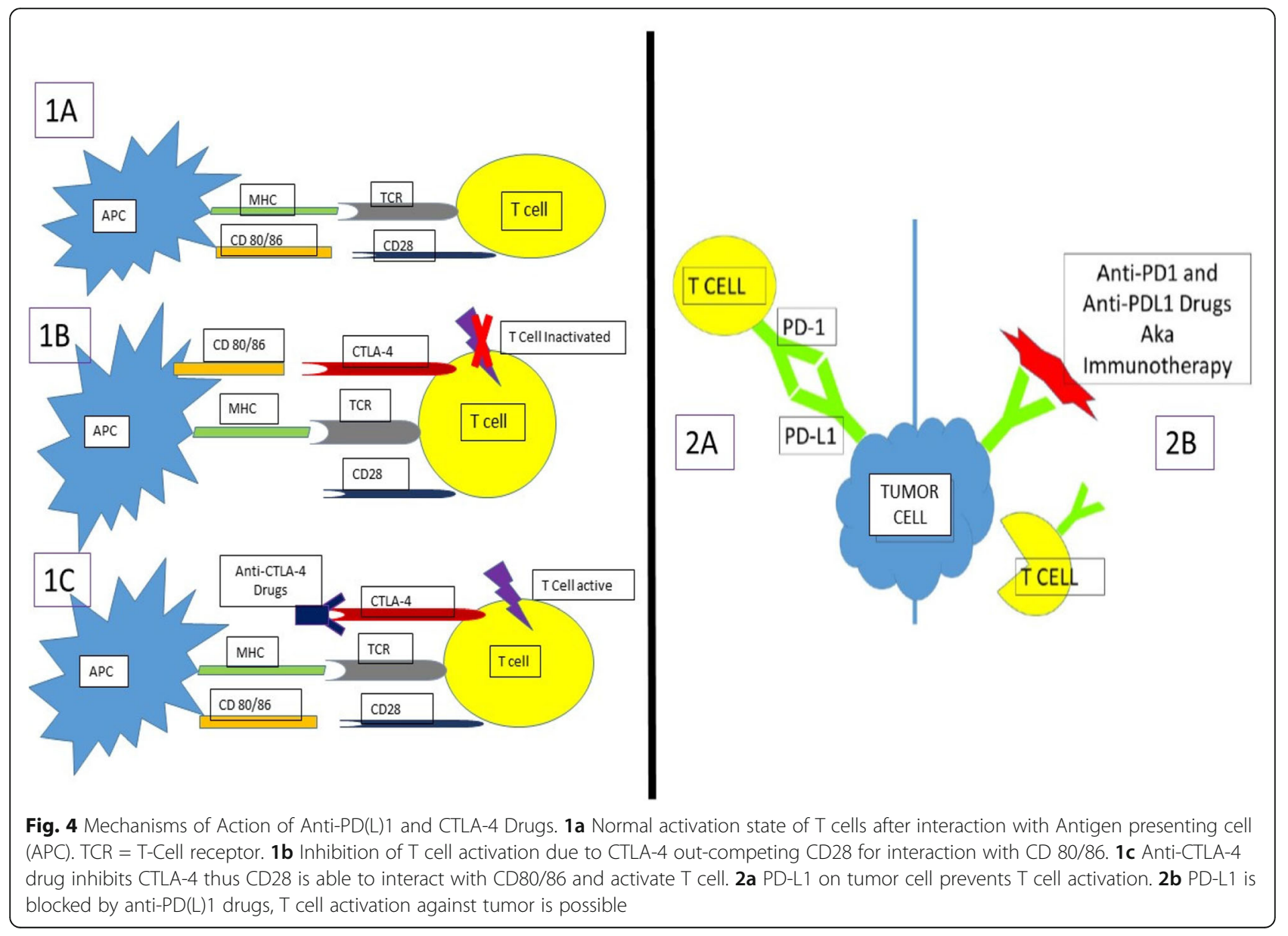


Many cases of diabetes following ICI therapy were reported in 2016 and 2017, after the anti-PD-1 drugs were approved in 2014. Prior to this, T1DM following ICI therapy was reported to be rare - (a) diabetes was not reported in a 2016 meta-analysis [198] (b) reported as $0.2-0.9 \%$ after anti-PD-1 and $0.1-0.3 \%$ after anti-PD-L1 therapy in 2017 [195], and (c) only 13 cases $(0.2 \%)$ in the 2018 systematic review and meta-analysis [199]. Our study identified 65 case reports of T1DM, many more than identified in meta-analysis of clinical trials [199]. In our study, 12 T1DM cases were fulminant T1DM - acute, recent onset of severe hyperglycemia with ketoacidosis with negative islet-related Abs in general [200]. Recently Stamatouli et al. reported that insulin-dependent diabetes induced with checkpoint inhibitors have similarities and differences when compared with classic T1DM [201].

\section{Case documentation}

Very few case reports in our review specified the severity of the endocrine irABs considered "required" when reporting adverse events [12]. However, based on the information in the case reports, most were Grade 2 or 3 with a few Grade 4 cases. Grading the severity of endocrinopathies can be helpful as some endocrine irABs are emergencies - DKA, adrenal crisis, thyroid storm and myxedema coma - and can be life threatening requiring urgent care. Similarly, the information on the personal and family history of the specific endocrine disorder or autoimmune disorder is sparse except for the DM cases. Finally, only 91/445 cases reported stopping the ICI drugs when the irAE occurred with insufficient information on whether they were transient or permanent. Of great interest is 1 patient with T1DM did not need insulin 81 days after pembrolizumab was discontinued [144].

\section{Limitations and strengths}

This scoping review has limitations. The first is the variability of information in published case reports. Some did not have all the data identified as "required" or "highly desirable" [12] but had enough to meet the study criteria. There was variability in the diagnostic tests done, including their timing. In the hypophysitis cases the pituitary imaging may be delayed and not all had pre-treatment imaging for comparison. Secondly, although almost all had close temporal relationship, there were a few irAEs which occurred much later $[45,56,94,102,144,147]$. Thirdly, although many cases reported were in full papers, 43 were abstracts as their full reports could not be located at the time of writing. Fourthly, our scoping study covered only published case reports mainly in post-marketing. Fifthly, our scoping review included case reports up to January 31, 2018. Since then other case reports have been published [193]. Finally, as pointed out in a systematic review [202], some reports on irAEs in clinical trials, as in our review, do not have all required information.

Our review has strengths: (a) It is comprehensive with data collected in a standardized way from before and after marketing published case reports and can uncover important irAEs not previously addressed. A 2018 meta-analysis [199] addressed only hypothyroidism, hyperthyroidism, hypophysitis, primary adrenal insufficiency and diabetes mellitus. (b) Using clinical reasoning, diagnoses were based on integrated clinical, biochemical and management documentation complemented by a temporal relationship between initiation of ICI and development of endocrinopathies [203]; (c) our study uncovered many more cases of ICI-induced T1DM than in a 2016 systematic review of irAEs case reports [9] and a 2018 meta-analysis of clinical trials data [199]; and (d) we report unique or first of a kind endocrinopathy $[122,127]$ not mentioned in prior systematic reviews and meta-analysis [199].

\section{Conclusion}

In closing, this scoping review mapped the changing landscapes of ICI-induced endocrinopathies before and after marketing of 1 anti-CTL4-1 mAb (approved 2011), 2 anti-PD-1 mAbs (approved 2014) and 3 anti-PDL-1 mAbs (approved 2016/2017). In mostly real-world patients, we uncovered a spectrum of endocrinopathies - in 5 glands with 12 endocrinopathies that manifest with symptoms of hormone excess or deficiency.

Case reports can alert physicians of a drug's AEs [12]. With increasing use of ICIs, physicians in many medical specialties (oncology, endocrinology, emergency medicine and primary care) should be vigilant for these ICI-induced endocrinopathies' occurrence and be able to diagnose and treat them. "Cross talk" for collaborative care between oncologists and endocrinologists has been proposed [204]. It is beyond the scope of this paper to cover algorithms and guidelines for the diagnosis and management of ICI-induced endocrinopathies in cancer patients. Some oncology centers [205, 206], National Oncology Societies [207, 208] and Society of Endocrinology Emergency Guidance document [209] have published algorithms and clinical practice guidelines. The reporting of endocrine irAEs can be improved [12, 202]. Our findings can help physicians manage their patients and professional societies develop their clinical practice guidelines. 


\section{Additional files}

Additional file 1: Appendix 1. Literature Search. (DOCX 16 kb)

Additional file 2: Appendix 2. Standardized Case Form for Data Collection. (DOCX $13 \mathrm{~kb})$

Additional file 3: Appendix 3. Cases of Immune Checkpoint InhibitorInduced Endocrinopathies -Hypophysitis and Anterior Hypopituitarism. (DOCX $51 \mathrm{~kb}$ )

Additional file 4: Appendix 4. Cases of Immune Checkpoint InhibitorsInduced Endocrinopathies - Thyroid Disorders: (a) Thyrotoxicosis (b) Hypothyroidism. (DOCX $48 \mathrm{~kb}$ )

Additional file 5: Appendix 5. Cases of Immune Checkpoint InhibitorsInduced Endocrinopathies -Diabetes Mellitus. (DOCX $41 \mathrm{~kb}$ )

Additional file 6: Appendix 6. Cases of Immune Checkpoint InhibitorInduced Endocrinopathies - Primary Adrenal Insufficiency, Cushing's Syndrome, Hypoparathyroidism, Diabetes Insipidus. (DOCX 22 kb)

\section{Abbreviations}

A1c: Glycated hemoglobin; ACTH: Adrenocorticotropic hormone; ADH: Antidiuretic hormone; Anti-CTLA-4: Anti-Cytotoxic T-lymphocyte-associated antigen-4; Anti-PD-1: Anti-programmed cell death protein-1; Anti-PDL-1: AntiProgrammed Death Ligand-1; Atezo: Atezolumab; AutoD: Autoimmune disease; Avelu: Avelumab; Ca: Carcinoma; C-pep: C-peptide;

$\mathrm{CRH}$ : Corticotropin releasing hormone; CST: Cosyntropin stimulation test; CT: Computerized tomography; CTCAE: Common terminology criteria for adverse events; D/C: Discontinued; DI: Diabetes insipidus; DKA: Diabetic ketoacidosis; EKG: Electrocardiogram; EndoD: Endocrine disease; FHx: Family history; FSH: Follicle stimulating hormone; FT3: Free triiodothyronine; FT4: Free thyroxine; GAD 65: Glutamic acid decarboxylase 65; GH: Growth hormone; HCT: Hydrocortisone; HD steroids: High dose steroids; IA-2: Islet antigen 2; IAA: Insulin auto-antibody; IGF1: Insulin growth factor-1; IgG: Immunoglobulin; Ipi: Ipilimumab; LH: Luteinizing hormone; LT4: Levothyroxine; MRI: Magnetic resonance imaging; Nivo: Nivolumab; NL: Normal; NR: Not reported; NSCLC: Non-small cell lung cancer; PAl: Primary adrenal insufficiency; Pembro: Pembrolizumab; PET: Positron emission tomography; PHx: Personal history; PRL: Prolactin; PTH: Parahormone; RAl: Radioactive iodine; RCC: Renal cell carcinoma; Rx: Treatment; SAI: Secondary adrenal insufficiency; SD: Standard deviation; T: Testosterone; T1DM: Type 1 diabetes mellitus; T2DM: Type 2 diabetes mellitus; TCR: T-cell receptor; TG: Thyroglobulin Ab; ThyD: Thyroid disease; TPO: Thyroperoxidase antibodies (Ab); TRAb: Thyroreceptor Ab; Treme: Tremelimumab; TSH: Thyroid stimulating hormone; TSI: Thyroid stimulating immunoglobulin; US: Ultrasound; Utomi: Utomilumab; ZnT8: Zinc Transporter 8; $\beta \mathrm{OB}$ : $\beta-\mathrm{OH}$ butyrate

\section{Acknowledgements}

None

\section{Funding}

None.

\section{Availability of data and materials}

Data supporting the findings and conclusion of this review are found in the Supplementary Materials section.

\section{Authors' contributions}

MHT, RG and BR conceived this scoping review and designed it with MPM who conducted the original and supplemental literature searches. LYS, RI, KMS, RG, and MHT collected, analyzed and interpreted the case reports. They were also involved in the hand search of references of articles and relevant journals from July 2017 to January 2018. SY, MPM and MHT prepared the first draft of the manuscript. Every author critically reviewed and revised the various drafts of the manuscripts before approving the final version for submission. MHT coordinated the preparation of this scoping review.

\section{Ethics approval and consent to participate} Not applicable.

\section{Consent for publication}

No patient consent needed.

\section{Competing interests}

None.

\section{Publisher's Note}

Springer Nature remains neutral with regard to jurisdictional claims in published maps and institutional affiliations.

\section{Author details}

${ }^{1}$ Division of Metabolism, Endocrinology \& Diabetes, Department of Internal Medicine, University of Michigan, 24 Frank Lloyd Wright Drive, Ann Arbor, M 48106, USA. ${ }^{2}$ Present address: Endocrinology, Rush University Medical Center, 1725 West Harrison Street, Chicago, IL 60612, USA. ²Division of Hematology/ Oncology, Department of Internal Medicine, University of Michigan, 1500 E. Medical Center Drive, Ann Arbor, MI 48109, USA. ${ }^{4}$ Taubman Health Sciences Library, University of Michigan, 1135 Catherine Street, Ann Arbor, Ml 48109, USA. ${ }^{5}$ Affiliated Hospital of QingDao University, QingDao, 16 Jiangsu Road, Sinan Qu, Qingdao, Shi, Shandong Sheng, China.

Received: 31 August 2018 Accepted: 29 November 2018 Published online: 22 January 2019

\section{References}

1. FDA. Pembrolizumab (KEYTRUDA) Prescribing Information 2017 [Available from: https://www.accessdata.fda.gov/drugsatfda_docs/label/2017/ 125514s031lbl.pdf Accessed 17 May 2018.

2. FDA. Nivolumab (OPDIVO) Prescribing Information 2017 [Available from: https://www.accessdata.fda.gov/drugsatfda_docs/label/2018/ 125554s035s036s037s038s039lbl.pdf Accessed 17 May 2018.

3. FDA. Ipilimumab (YERVOY) Prescribing Information 2017 [Available from: https://www.accessdata.fda.gov/drugsatfda_docs/label/2017/125377s091lbl. pdf Accessed 17 May 2018

4. FDA. Atezolizumab (TECENTRIQ) Prescribing Information. 2018 [cited 2018; Available from: https://www.accessdata.fda.gov/drugsatfda_docs/label/2018/ 761034s005lbl.pdf Accessed 17 May 2018.

5. FDA. Durvalumab (IMFINZI) Prescribing Information. 2018 [cited 2018; Available fro Accessed 17 May 2018.

6. FDA. Avelumab (BAVENCIO) Prescribing Information. 2017 [cited 2018; Available from:https://www.accessdata.fda.gov/drugsatfda_docs/label/2017/ 761049s000lbl.pdf Accessed 17 May 2018.

7. Min L. Immune-related endocrine disorders in novel immune checkpoint inhibition therapy. Genes Dis. 2016:3:252-6.

8. Min L, Hodi FS, Giobbie-Hurder A, Ott PA, Luke JJ, Donahue H, et al. Systemic high-dose corticosteroid treatment does not improve the outcome of ipilimumab-related hypophysitis: a retrospective cohort study. Clin Cancer Res. 2015:21:749-55.

9. Abdel-Wahab N, Shah M, Suarez-Almazor ME. Adverse events associated with immune checkpoint blockade in patients with cancer: a systematic review of case reports. PLoS One. 2016;11:e0160221.

10. Arksey H, O'Malley L. Scoping studies: towards a methodological framework Int J Soc Res Methodol. 2005:8:19-32.

11. Levac D, Colquhoun H, O'Brien KK. Scoping studies: advancing the methodology. Implement Sci. 2010;5:69.

12. Kelly WN, Arellano FM, Barnes J, Bergman U, Edwards RI, Fernandez AM, et al. Guidelines for submitting adverse event reports for publication. Drug Saf. 2007;30:367-73

13. Phan GQ, Yang JC, Sherry RM, Hwu P, Topalian SL, Schwartzentruber DJ, et al. Cancer regression and autoimmunity induced by cytotoxic $T$ lymphocyte-associated antigen 4 blockade in patients with metastatic melanoma. Proc Natl Acad Sci U S A. 2003;100:8372-7.

14. Blansfield J, Beck K, Tran K, Yang JC, Hughes M, Kammula U, et al. Cytotoxic T-Lymphocyte-associated antigen-4 blockage can induce autoimmune hypophysitis in patients with metastatic melanoma and renal cancer. J Immunother. 2005:28:593-8.

15. Shaw SA, Camacho LH, McCutcheon IE, Waguespack SG. Transient hypophysitis after cytotoxic T lymphocyte-associated antigen 4 (CTLA4) blockade. J Clin Endocrinol Metab. 2007;92:1201-2.

16. Yang JC, Hughes M, Kammula U, Royal R, Sherry R, Topalian SL, et al. Ipilimumab (anti-CTLA4 antibody) causes regression of metastatic renal cell 
cancer associated with enteritis and Hypophysitis. J Immunother. 2007;30:825-30.

17. Kaehler KC, Egberts F, Lorigan P, Hauschild A. Anti-CTLA-4 therapy-related autoimmune hypophysitis in a melanoma patient. Melanoma Res. 2009 Oct; 19(5):333-4

18. Carpenter KJ, Murtagh RD, Lilienfeld H, Weber J, Murtagh FR. Ipilimumabinduced hypophysitis: MR imaging findings. AJNR Am J Neuroradiol. 2009; 30:1751-3.

19. Dillard T, Yedinak CG, Alumkal J, Fleseriu M. Anti-CTLA-4 antibody therapy associated autoimmune hypophysitis: serious immune related adverse events across a spectrum of cancer subtypes. Pituitary. 2010;13:29-38.

20. Min L, Vaidya A, Becker C. Association of ipilimumab therapy for advanced melanoma with secondary adrenal insufficiency: a case series. Endocr Pract. 2012;18:5.

21. Andrews $\mathrm{S}$, Holden R. Characteristics and management of immune-related adverse effects associated with ipilimumab, a new immunotherapy for metastatic melanoma. Cancer Manag Res. 2012;4:299-307.

22. Barnard ZR, Walcott BP, Kahle KT, Nahed BV, Coumans JV. Hyponatremia associated with Ipilimumab-induced hypophysitis. Med Oncol. 2012;29: 374-7.

23. Juszczak A, Gupta A, Karavitaki N, Middleton MR, Grossman AB. Ipilimumab: a novel immunomodulating therapy causing autoimmune hypophysitis: a case report and review. Eur J Endocrinol. 2012;167:1-5.

24. Carra T, Gaudy-Marqueste C, Albarel F, Monestier S, Mallet S, Brue T, et al. Ipilimumab-induced hypophysitis in melanoma patients. J Clin Oncol. 2012; 30(15):1.

25. Eranki VG, Elhomsy G, Silverberg A, Albert S. Ipilimumab-associated hypophysitis-time course of MRI and hormonal changes. Endocr Rev. 2012; 33:2012-06.

26. Kwun S, Lukacova-Zib I, Gopalakrishnan G. Central adrenal insufficiency and hypothyroidism after ipilimumab treatment. Endocr Rev. 2012;33:2012-06.

27. Lammert A, Schneider HJ, Bergmann T, Benck U, Kramer BK, Gartner R, et al. Hypophysitis caused by ipilimumab in cancer patients: hormone replacement or immunosuppressive therapy. Exp Clin Endocrinol Diabetes. 2013;121:581-7.

28. Anderson L, Bhatia V. Ipilimumab immune. related adverse reactions: a case report. S D J Med. 2013;66:4.

29. Leonard D, et al. Hyponatremia and hypopituitarism secondary to Ipilimumab. Am J Kidney Dis. 2013;61:A59.

30. Sarvaideo JL, Block RJ, Brockstein B, Meyer J. Adrenal crisis secondary to hypophysitis after ipilimumab therapy and steroid treatment. Endocr Rev. 2013;34:2013-06.

31. Thompson BM, Joshi R. Ipilimumab-induced hypophysitis and thyroiditis. Endocr Rev. 2013;34:2013-06

32. Ahmed MK, Rein V, Shenker Y, Albertini M, Davis DB. Central adrenal insufficiency due to ipilimumab (Yervoy). Endocr Rev. 2013;34:2013-06

33. Gil SM, Aparicio M, Bertini K, Rodriguez F, Sankowicz S, Ballarino C, et al. Autoimmune hypophysitis due to ipilimumab. Endocr Rev. 2013;34:2013-06.

34. Min L, Ibrahim N. Ipilimumab-induced autoimmune adrenalitis. Lancet Diabetes Endocrinol. 2013;1(3):e15.

35. Assi H, Wilson KS. Immune toxicities and long remission duration after ipilimumab therapy for metastatic melanoma: two illustrative cases. Curr Oncol. 2013:20:e165-9.

36. de Hollanda A, Aranda GB, Mora M, Gaba L, Halperin I. Ipilimumab, a cause of autoimmune hypophysitis. Endocrinología y Nutrición (English Edition). 2013;60:604-6

37. Hermes I, Tsiogka M, Rompoti N, Suttorp W, Zimmer L, Schadendorf D. Autoimmune hypophysitis, autoimmunolitis and autoimmune hepatitis in a patient with metastatic melanoma under CTLA-4 therapy antibody ipilimumab. J Dtsch Dermatol Ges. 2013;11:932.

38. Burgess D, Loh KP, Lee SY, Ali S. Sixth cranial palsy as an unusual presenting symptom of ipilimumab induced hypophysitis. J Gen Intern Med. 2013; 28(S1):S390-1

39. Chodakiewitz Y, Brown S, Boxerman JL, Brody JM, Rogg JM. I pilimumab treatment associated pituitary hypophysitis: clinical presentation and imaging diagnosis. Clin Neurol Neurosurg. 2014;125:125-30.

40. Rodrigues BT, Otty Z, Sangla K, Shenoy W. Ipilimumab-induced autoimmune hypophysitis: a differential for sellar mass lesions. Endocrinol Diabetes Metab Case Rep. 2014;2014:140098.

41. Nallapaneni N, Mourya R, Bhatt V, Malhotra S, Ganti A, Tendulkar K. Ipilimumab-induced hypophysitis and uveitis in a patient with metastatic melanoma and a history of ipilimumab-induced skin rash. J Natl Compr Canc Netw. 2014;12:5.

42. Faje AT, Sullivan R, Lawrence D, Tritos NA, Fadden R, Klibanski A, et al. Ipilimumab-induced hypophysitis: a detailed longitudinal analysis in a large cohort of patients with metastatic melanoma. J Clin Endocrinol Metab. 2014;99:4078-85.

43. Buddhdev K, Buddhdev B. A rare case of Ipilimumab induced pituitary Hypophysitis: an evolving clinical entity. Endocr Soc. 2014;35(4 Suppl):677

44. Marlier J, Cocquyt V, Brochez L, Van Belle S, Kruse V. Ipilimumab, not just another anti-cancer therapy: hypophysitis as side effect illustrated by four case-reports. Endocrine. 2014:47(3):878-83.

45. Ryder M, Callahan M, Postow MA, Wolchok J, Fagin JA. Endocrine-related adverse events following ipilimumab in patients with advanced melanoma: a comprehensive retrospective review from a single institution. Endocr Relat Cancer. 2014;21:371-81.

46. Alkhaddo J, Khowaja A, Saeed A, Burmeister L. Serial TSH levels during treatment and onset of ipilimumab-induced hypophysitis. failure of tsh alone to make the diagnosis. Endocr Soc. 2014;35(4 Suppl):676

47. Iwama S, de Remigis A, Callahan MK, Slovin S, Wolchok JD, Caturegli P. Pituitary expression of CTLA-4 mediates hypophysitis secondary to administration of CTLA-4 blocking antibody. Sci Transl Med. 2014;6:230ra45.

48. Tiu C, Pezaro C, Davis ID, Grossmann M, Parente P. Early recognition of ipilimumab-related autoimmune hypophysitis in patients with metastatic melanoma: case studies and recommendations for management. Asia Pac J Clin Oncol. 2015;11:190-4.

49. Kotwal A, Rao S, Haas RA. Ipilimumab induced hypophysitis may not affect all pituitary cell lines: a case study. Endocr Rev. 2015;36(2):2015-03.

50. Denman D, Mongelluzzo G, Lock J, Panikkar R, Zeng Y, Gingrich P, et al. The growing concern for autoimmune hypophysitis due to ipilimumab. Endocr Rev. 2015;36(2 Suppl):469.

51. Heaney AP, Sumerel B, Rajalingam R, Bergsneider M, Yong WH, Liau LM. HLA markers DQ8 and DR53 are associated with lymphocytic Hypophysitis and may aid in differential diagnosis. J Clin Endocrinol Metab. 2015;100: 4092-7.

52. Majchel D, Korytkowski MT. Anticytotoxic T-lymphocyte antigen-4 induced autoimmune hypophysitis: a case report and literature review. Case Rep Endocrinol. 2015;2015:570293.

53. Lam T, Chan MM, Sweeting AN, De Sousa SM, Clements A, Carlino MS, et al. Ipilimumab-induced hypophysitis in melanoma patients: an Australian case series. Intern Med J. 2015;45:1066-73.

54. DeSousa S, Long GV, Tonks K. Ipilimumab-induced hypophysitis: early Australian experience. MJA. 2014;201:2.

55. Hanseree P, Poehls J. Ipilimumab induced Hypophysitis - recurrence of symptoms during the course of steroid treatment. Endocr Soc. 2015:36(2 Suppl):470.

56. Albarel F, Gaudy C, Castinetti F, Carre T, Morange I, Conte-Devolx B, et al. Long-term follow-up of ipilimumab-induced hypophysitis, a common adverse event of the anti-CTLA-4 antibody in melanoma. Eur J Endocrinol. 2015;172:195-204

57. Araujo PB, Coelho MC, Arruda M, Gadelha MR, Neto LV. Ipilimumab-induced hypophysitis: review of the literature. J Endocrinol Investig. 2015;38:1159-66.

58. Carl D, Grullich C, Hering S, Schabet M. Steroid responsive encephalopathy associated with autoimmune thyroiditis following ipilimumab therapy: a case report. BMC Res Notes. 2015;8:316.

59. Mahzari M, Liu D, Arnaout A, Lochnan H. Immune checkpoint inhibitor therapy associated hypophysitis. Clin Med Insights Endocrinol Diabetes. 2015;8:21-8.

60. Yun S, Vincelette ND, Mansour I, Hariri D, Motamed S. Late onset ipilimumab-induced pericarditis and pericardial effusion: a rare but lifethreatening complication. Case Rep Oncol Med. 2015;2015:794842. pp. 1-5.

61. Wilson MA, Guld K, Galetta S, Walsh RD, Kharlip J, Tamhankar M, et al. Acute visual loss after ipilimumab treatment for metastatic melanoma. J Immunother Cancer. 2016:4:66.

62. Ohnuma T, Matsuzawa T, Kinoshita M, Sano S, Kawamura T, Shimada S, et al. Case of metastatic uveal melanoma in which an antitumor effect appeared after ipilimumab discontinuation due to autoimmune hypophysitis. J Dermatol. 2017;44:1325-6.

63. Grenier M, Maditz R, Pabbathi S. Can't cope with the stress of nivolumab therapy: immune mediated adrenal insufficiency [abstract]. J Hosp Med. 2016;11(suppl 1). https://www.shmabstracts.com/abstract/cant-cope-withthe-stress-of-nivolumab-therapyimmune-mediated-adrenal-insufficiency/.

64. Caturegli P, Di Dalmazi G, Lombardi M, Grosso F, Larman HB, Larman T, et al. Hypophysitis secondary to cytotoxic T-lymphocyte-associated protein 4 
blockade: insights into pathogenesis from an autopsy series. Am J Pathol. 2016;186:3225-35.

65. Marques $P$, Grossman A. Ipilimumab-induced autoimmune Hypophysitis: diagnostic and management challenges illustrated by a clinical case. Acta Medica Port. 2015;28:6.

66. Koessler T, Olivier T, Fertani S, Marinari E, Dutoit V, Dietrich P. Ipilimumabrelated hypophysitis may precede severe CNS immune attack. Ann Oncol. 2016;27:2.

67. Okano Y, Satoh T, Horiguchi K, Toyoda M, Osaki A, Matsumoto S, et al. Nivolumab-induced hypophysitis in a patient with advanced malignant melanoma. Endocr J. 2016;63:8.

68. Miller AH, Brock P, Jim Yeung SC. Pituitary dysfunction: a case series of immune checkpoint inhibitor-related Hypophysitis in an emergency department. Ann Emerg Med. 2016;68:249-50.

69. Todd A. Adrenal insufficiency secondary to ipilimumab induced hypophysitis: the northern Irish experience. Ir J Med Sci. 2016;185(Suppl 7): 363-419.

70. Freeman-Keller M, Kim Y, Cronin H, Richards A, Gibney G, Weber JS. Nivolumab in resected and Unresectable metastatic melanoma: characteristics of immune-related adverse events and association with outcomes. Clin Cancer Res. 2016;22:886-94.

71. Vancieri G, Beilla A, Lauro D. Lat-onset panhypopituitarism in a 72-year-old male patient with ipilimumab for metastatic melanoma: a case report. J Endocrinol Investig. 2016;39:805-6.

72. Chon D, Robertson AM, Bhat S. Novel immunomodulating therapy ipilimumab induced acute adrenal insufficiency secondary to autoimmune hypophysitis in a patient with squamous cell lung carcinoma. Endocr Rev. 2016;37:2016-04.

73. Gill PM, Story ES. A case of pituitary failure following treatment with ipilimumab. J Gen Intern Med. 2016;31(2 SUPPL 1):S493-S4.

74. Telford R, Patel AJ, Roberson G, Bag A. Ipilimumab-induced hypophysitis. Endocr Rev. 2016;37:2016-04

75. Humanyun MA, Poole R. A case of multiple immune toxicities from Ipilimumab and pembrolizumab treatment. Hormones. 2016;15:303-6.

76. Lowe JR, Perry DJ, Salama AK, Mathews CE, Moss LG, Hanks BA. Genetic risk analysis of a patient with fulminant autoimmune type 1 diabetes mellitus secondary to combination ipilimumab and nivolumab immunotherapy. J Immunother Cancer. 2016:4:89.

77. Bot I, Blank CU, Boogerd W, Brandsma D. Neurological immune-related adverse events of ipilimumab. Pract Neurol. 2013;13:278-80.

78. Ishikawa M, Oashi K. Case of hypophysitis caused by nivolumab. J Dermatol. 2017:44:109-10

79. Mansoor S, Hall R, Mihalek A. Use of immune checkpoint inhibitors induces an immune mediated Hypophysitis. Am J Respir Critical Care Med. 2017;195:1.

80. Konda B, Nabhan F, Shah MH. Endocrine dysfunction following immune checkpoint inhibitor therapy. Curr Opin Endocrinol Diabetes Obes. 2017;24: 337-47.

81. Fujimura T, Kambayashi Y, Furudate S, Kakizaki A, Hidaka T, Haga T, et al. Isolated adrenocorticotropic hormone deficiency possibly caused by nivolumab in a metastatic melanoma patient. J Dermatol. 2017:44:e13-e4.

82. Oda T, Sawada Y, Okada E, Yamaguchi T, Ohmori S, Haruyama S, et al. Hypopituitarism and hypothyroidism following atrioventricular block during nivolumab treatment. J Dermatol. 2017;44:e144-e5.

83. Neril R, Lorton J, Zonszein J. Nivolumab-induced isolated adrenal insufficiency: a case report. AACE Clin Case Rep. 2017;3(3):e210-e2.

84. Narahira A, Yanagi T, Cho KY, Nakamura A, Miyoshi H, Hata H, et al. Isolated adrenocorticotropic hormone deficiency associated with nivolumab therapy. J Dermatol. 2017 Apr;44(4):e70.

85. Kitajima K, Ashida K, Wada N, Suetsugul R, Takeichi Y, Sakamoto S, et al. Isolated ACTH deficiency probably induced by autoimmune-related mechanism evoked with nivolumab. Jap J Clin Oncol. 2017:47:463-6.

86. Brilli L, Danielli R, Ciuoli C, Calabro L, Di Giacomo AM, Cerase A, et al. Prevalence of hypophysitis in a cohort of patients with metastatic melanoma and prostate cancer treated with ipilimumab. Endocrine. 2017; 58:535-41.

87. Singh D, Hsu CC, Kwan GN, Bhuta S. Ipilimumab-induced hypophysitis and ileocolitis: serial pituitary MRI findings. Neurol India. 2017;65(1):165-6.

88. Otsubo K, Nakatomi K, Furukawa R, Ashida K, Yoneshima Y, Nakanishi Y, et al. Two cases of late-onset secondary adrenal insufficiency after discontinuation of nivolumab. Ann Oncol. 2017;28:3106-7.
89. Anderson C, McKenna S, Santos A, Westrup J, Kelleher F, Griffin M, et al. Hypophysitis secondary to the checkpoint inhibitor Pembrolizumab-a rare condition, a new cause-a case report. Irish J Med Sci. 2017;186(9 Supplement 1):S355-S6.

90. Bhalla S, Hauck K. Hypophysitis and adrenal insufficiency secondary to ipilimumab and nivolumab: A nearly life-threatening side effect of novel immunotherapy agents. J Gen Intern Med. 2017;32(2 Supplement 1):S514.

91. Mian N, Rukmangadachar L, Choucair A. Ipilimumab induced auto-immune hypophysitis. Ann Neurol. 2017;82(Supplement 21):S29.

92. Okiro J, McHugh CM. Ipilimumab induced hypophysitis, pathogenesis and review of current literatures. Irish J Med Sci. 2017;186(9 Supplement 1):S379.

93. Zeng MF, Chan L, Ye HY, Gong W, Zhou LN, Li YM, et al. Primary hypothyroidism and isolated ACTH deficiency induced by nivolumab therapy -case report and review. Medicine. 2017;96(44):e8426.

94. Takaya K, Sonoda M, Hiyoshi T. Isolated adrenocorticotropic hormone deficiency caused by nivolumab in a patient with metastatic lung cancer. Intern Med. 2017:56:2463-9.

95. Marchand L, Paulus V, Fabien N, Perol M, Thivolet C, Santignyu P. Nivolumab-induced acute diabetes mellitus and Hypophysitis in a patient with advanced pulmonary pleomorphic carcinoma with a prolonged tumor response. J Thorac Oncol. 2017;12:e182-4.

96. Kanie K, Iguchi G, Bando H, Fujita Y, Odake Y, Yoshida K, et al. Two cases of Atezolizumab-induced Hypophysitis. J Endocr Soc. 2018;2:91-5.

97. Min L, Vaidya A, Becker C. Thyroid autoimmunity and ophthalmopathy related to melanoma biological therapy. Eur J Endocrinol. 2011;164:303-7.

98. Borodic G, Hinkle D, Cia Y. Drug-induced graves' disease from CTLA-4 receptor suppression. Ophthal Plast Reconstr Surg. 2011;27:1.

99. Borordic G, Hinkle D. Ipilimumab-induced orbital inflammation resembling graves disease with subsequent development of systemic hyperthyroidism from CTLA-4 receptor suppression. Ophthal Plast Reconstr Surg. 2014;30:83.

100. Krull I, Rogowski-Lehmann N, Sigrist S, Siano M, Brandle M, Bilz S. Thyroid dysfunction in a patient treated with Ipilimumab: autoimmune thyroid disease associated with AntiCTLA4 therapy. Endocr Soc. 2014; 35(4 Suppl):494

101. Azmat U, Liebner D, Joehlin-Price A, Agrawal A, Nabhan F. Treatment of Ipilimumab induced Graves' disease in a patient with metastatic melanoma. Case Rep Endocrinol. 2016;2016:2087525.

102. Gan EH, Mitchell AL, Plummer R, Pearce S, Perros P. Tremelimumab-induced graves hyperthyroidism. Eur Thyroid J. 2017/;6:167-70.

103. Orlov S, Salari F, Kashat L, Walfish PG. Induction of painless thyroiditis in patients receiving programmed death 1 receptor immunotherapy for metastatic malignancies. J Clin Endocrinol Metab. 2015;100:1738-41.

104. Verma I, Modi A, Tripathi H, Agrawal A. Nivolumab causing painless thyroiditis in a patient with adenocarcinoma of the lung. BMJ Case Rep. 2016;1-3. https:/ doi.org/10.1136/bcr2015-213692

105. Yu C, Chopra IJ, Ha E. A novel melanoma therapy stirs up a storm: ipilimumab-induced thyrotoxicosis. Endocrinol Diabetes Metab Case Rep. 2015;2015:140092.

106. Ferdousy F, Williams C, Sherman B, Fouty B, Vu M. Where is the storm coming from: a case of thyroid storm secondary to Ipilimumab. Chest. 2016; 150(4):379A.

107. Panach K, Oo Y. Nivolumab-induced thyroiditis in a patient with metastatic renal cell carcinoma. Thyroid. 2016;26(Supplement 1):A14.

108. JMM P, Kung JT. Silent (painless) thyroiditis induced by newest PD-1 inhibitor pembrolizumab. Endocr Rev. 2016;37:2016-04.

109. Somasundaram A, UKrainski M, Ahmed I, Fallon JJ Jr. Ipilimumab and pembrolizumab induced thyroiditis. Endocr Rev. 2015;36:2003-15.

110. McMillen B, Dhillon MS, Yong-Yow S. A rare case of thyroid storm. BMJ Case Rep. 2016;1-4. https://doi.org/10.1136/bcr:2016-214603.

111. Narita T, Oiso N, Taketomo Y, Okahashi K, Yamauchi K, Sato M, et al. Serological aggravation of autoimmune thyroid disease in two cases receiving nivolumab. J Dermatol. 2016:43:210-4.

112. Tanaka R, Fujisawa Y, Maruyama H, Nakamura Y, Yoshino K, Ohtsuka M, et al. Nivolumab-induced thyroid dysfunction. Jpn J Clin Oncol. 2016;46:575-9.

113. Besemer B, Mussig K. Rare differential diagnosis of hyperthyroidism. Dtsch Med Wochenschr. 2016;141(12):889.

114. Yu D, Kapoor A. Treatment with nivolumab results in asymptomatic thyroiditis followed by severe hypothyroidism. A Thyroid. 2016; 26(Supplement 1):A95.

115. Delivanis DA, Gustafson MP, Bornschlegl S, Merten MM, Kottschade L, Withers $\mathrm{S}$, et al. Pembrolizumab-induced thyroiditis: comprehensive clinical 
review and insights into underlying involved mechanisms. J Clin Endocrinol Metab. 2017;102(8):2770-80.

116. Diamantopoulos PT, Gaggadi M, Kassi E, Benopoulou O, Anastasopoulou A, Gogas H. Late-onset nivolumab-mediated pneumonitis in a patient with melanoma and multiple immune-related adverse events. Melanoma Res. 2017;27:391-5

117. Morganstein DL, Lai Z, Spain L, Diem S, Levine D, Mace C, et al. Thyroid abnormalities following the use of cytotoxic T-lymphocyte antigen-4 and programmed death receptor protein-1 inhibitors in the treatment of melanoma. Clin Endocrinol. 2017;86:614-20.

118. Nandavaram S, Nadkami A. Ipilimumab-Induced Sarcoidosis and Thyroiditis. Am J Therapeutics. 2018;25:e379-e380.

119. Osorio JC, Ni A, Chaft JE, Pollina R, Kasler MK, Stephens D, et al. Antibodymediated thyroid dysfunction during T-cell checkpoint blockade in patients with non-small-cell lung cancer. Ann Oncol. 2017;28:583-9.

120. Sweeting AN, Lomax A, Lim J, Cheng R, McGill N, Lowe P, et al. Pembrolizumab-induced thyroiditis in patients with metastatic melanoma: a novel form of autoimmune thyroid disease. Clin Endocrinol. 2017; 86(Supplement 1):34-5.

121. van Kooten M, Van den Berg G, Glaudemans A, Hiltermann T, Groen H, Rutgers A, et al. Transient thyrotoxicosis during nivolumab tr eatment. Neth J Med. 2017;75(5):4.

122. Win MA, Thein KZ, Qdaisat A, Yeung SJ. Acute symptomatic hypocalcemia from immune checkpoint therapy-induced hypoparathyroidism. Am J Emerg Med. 2017;35:1039 e5-7.

123. Yamauchi I, Sakane Y, Fukuda Y, Fujii T, Taura D, Hirata M, et al. Clinical features of Nivolumab-induced thyroiditis: a case series study. Thyroid. 2017; 27:894-901.

124. Okiyama N, Tanaka R. Varied immuno-related adverse events induced by immune-check point inhibitors - Nivolumab-associated psoriasiform dermatitis related with increased serum level of interleukin-6. Japan J Clin Immunol. 2017:40:7.

125. O'Malley G, Lee HJ, Parekh S, Galsky MD, Smith CB, Friedlander P, et al. Rapid evolution of thyroid dysfunction in patients treated with Nivolumab. Endocr Pract. 2017;23:1223-31.

126. Paepegaey AC, Lheure C, Ratour C, Lethielleux G, Clerc J, Bertherat J, et al. Polyendocrinopathy resulting from Pembrolizumab in a patient with a malignant melanoma. J Endocr Soc. 2017;1:646-9.

127. Lupu J, Pages C, Laly P, Delyon J, Laloi M, Petit A, et al. Transient pituitary ACTH-dependent Cushing syndrome caused by an immune checkpoint inhibitor combination. Melanoma Res. 2017;27(6):649-52.

128. Alhusseini M, Samantray J. Autoimmune diabetes superimposed on type 2 diabetes in a patient initiated on immunotherapy for lung cancer. Diabetes Metab. 2017;43:2.

129. Reddy SC, Darapu H, Agarwal M. Nivolumab induced auto-immune diabetes mellitus and thyroiditis: a case report. Endocr Rev. 2017;38(3):2004-17.

130. Sakurai K, Nitsuma S, Sato R, Takahashi K, Arihara Z. Painless thyroiditis and fulminant type 1 diabetes mellitus in a patient treated with an immune checkpoint inhibitor, Nivolumab. Tohoku J Exp Med. 2018;244:33-40.

131. Min L, Hodi FS. Anti-PD1 following ipilimumab for mucosal melanoma: durable tumor response associated with severe hypothyroidism and rhabdomyolysis. Cancer Immunol Res. 2014;2:15-8.

132. Mellati M, Eaton KD, Brooks-Worrell BM, Hagopian WA, Martino R, Palmer JP. Anti-PD-1 and anti-PDL-1 monoclonal antibodies causing type 1 diabetes mellitus. Diabetes Care. 2015;38:e137-8.

133. Khan U, Rizvi H, Sano D, Chiu J, Hadid T. Nivolumab induced myxedema crisis. J Immunother Cancer. 2017;5:13.

134. Li L, Masood A, Bari S, Yavuz S, Grosbach AB. Autoimmune diabetes and thyroiditis complicating treatment with Nivolumab. Case Rep Oncol. 2017;10:230-4

135 Imafuku K, Yoshino K, Yamaguchi K, Tsuboi S, Ohara K, Hata H. Hypothyroidism associated with Nivolumab treatment of Unresectable malignant melanoma. Clin Exp Dermatol. 2017:42:217-8.

136. Guaraldi F, La Selva R, Sama MT, D'Angelo V, Gori D, Fava P, et al. Characterization and implications of thyroid dysfunction induced by immune checkpoint inhibitors in real-life clinical practice: a long-term prospective study from a referral institution. J Endocrinol Investig. 2018;41:549-56.

137. Di Lucca G, Rossini C, Morena R, Banfi L, Pogliani C, Parati MC, et al. Association between the development of autoimmune hypothyroidism and objective response to nivolumab: report of two cases. Ann Oncol. 2017; 28(Supplement 6):vi99.
138. Torimoto K, Okada Y, Nakayamada S. Anti-PD-1 antibody therapy induces Hashimoto's disease with an increase in peripheral blood follicular helper $\mathrm{T}$ cells. Thyroid. 2017;27:1335-6.

139. Gaudy C, Clevy C, Monestier S, Dubois N, Preau Y, Mallet S, et al. Anti-PD1 Pembrolizumab Can induce exceptional fulminant type 1 diabetes. Diabetes Care. 2015;38:e182-3.

140. Hughes J, Vudattu N, Sznol M, Gettinger S, Kluger H, Lupsa B, et al. Precipitation of autoimmune diabetes with anti-PD-1 immunotherapy. Diabetes Care. 2015:38:e55-7.

141. Martin-Liberal J, Furness AJ, Joshi K, Peggs KS, Quezada SA, Larkin J. Antiprogrammed cell death-1 therapy and insulin-dependent diabetes: a case report. Cancer Immunol. 2015;64:765-7.

142. Aleksova J, Lau PK, Soldatos G, McArthur G. Glucocorticoids did not reverse type 1 diabetes mellitus secondary to pembrolizumab in a patient with metastatic melanoma. BMJ Case Rep. 2016;1-5. https://doi.org/10.1136/bcr: 2016-217454.

143. Akturk H, Meek S, Joseph R. Nivolumab Related Insulin-dependent. Diabetes. 2016;65:A414.

144. Hansen E, Sahasrabudhe D, Sievert L. A case report of insulin-dependent diabetes as immune-related toxicity of pembrolizumab: presentation, management and outcome. Cancer Immunol. 2016;65:3.

145. Hofmann L, Forschner A, Loquai C, Goldinger SM, Zimmer L, Ugurel S, et al. Cutaneous, gastrointestinal, hepatic, endocrine, and renal side-effects of anti-PD-1 therapy. Eur J Cancer. 2016;60:190-209.

146. Miyoshi Y, Ogawa O, Oyama Y. Nivolumab, an anti-programmed cell Death-1 antibody, induces fulminant type 1 diabetes. Tohoku J Exp Med. 2016;239:4.

147. Okamoto M, Okamoto M, Gotoh K, Masaki T, Ozeki Y, Ando H, et al. Fulminant type 1 diabetes mellitus with anti-programmed cell death-1 therapy. J Diabetes Invest. 2016;7:915-8 PubMed.

148. Usui Y, Udagawa H, Matsumoto S, Imai K, Ohashi K, Ishibashi M, et al. Association of Serum Anti-GAD antibody and HLA haplotypes with type 1 diabetes mellitus triggered by Nivolumab in patients with non-small cell lung cancer. J Thorac Oncol. 2017:12:e41-e3.

149. Kong SH, Lee SY, Yang YS, Kim TM, Kwak SH. Anti-programmed cell death 1 therapy triggering diabetic ketoacidosis and fulminant type 1 diabetes. Acta Diabetol. 2016;53:853-6.

150. Shah M, Maxfield L, Feroz R, Donohue K. Rapid development of type 1 diabetes mellitus after initiation of anti-PD-1 therapy. Int J Cancer Clin Res. 2016;3:066-7.

151. Zaied A, Lee A. Nivolumab-induced autoimmune diabetic ketoacidosis. Chest. 2016:150:255A.

152. Tsiogka A, Jansky GL, Bauer JW, Koelblinger P. Fulminant type 1 diabetes after adjuvant ipilimumab therapy in cutaneous melanoma. Melanoma Res. 2017;27:524-5.

153. Abdul Aziz MHF, Fernando IP, Lenkanpally A, Fernando DS. Diabetic ketoacidosis after treatment with Pembrolizumab. J Clin Transl Endocrinol Case Rep. 2017;5:4-5.

154. Chae YK, Chiec L, Mohindra N, Gentzler R, Patel J, Giles F. A case of pembrolizumab-induced type-1 diabetes mellitus and discussion of immune checkpoint inhibitor-induced type 1 diabetes. Cancer Immunol Immunother CII. 2017;66:25-32.

155. Teramoto Y, Nakamura Y, Asami Y, Imamura T, Takahira S, Nemoto M, et al. Case of type 1 diabetes associated with less-dose nivolumab therapy in a melanoma patient. J Dermatol. 2016;44:2.

156. Thoreau B, Gouaillier-Vulcain F, Machet L, Mateus C, Robert C, FerreiraMaldent $\mathrm{N}$, et al. Acute lower limb Ischaemia and diabetes in a patient treated with anti-PD1 monoclonal antibody for metastatic melanoma. Acta Derm Venereol. 2017;97:408-9.

157. Araujo M, Ligeiro D, Costa L, Marque F, Trindade H, Correia J, et al. A case of fulminant type 1 diabetes following anti-PD1 immunotherapy in a genetically susceptible patient. Immunotherapy. 2017;9:6.

158. Atkins PW, Thompson DM. Combination avelumab and utomilumab immunotherapy can induce diabetic ketoacidosis. Diabetes Metab. 2018;44: 514-5

159. Chan JTK, Jones E. Nivolumab-induced autoimmune diabetes. J Pharm Pract Res. 2017:47(2):136-9.

160. Chan PY, Hall P, Hay G, Cohen VML, Szlosarek PW. A major responder to ipilimumab and nivolumab in metastatic uveal melanoma with concomitant autoimmunity. Pigment Cell Melanoma Res. 2017;30:558-62 
161. Daltry S, Bujanova J, Cranston I. Autoimmune diabetes and antiprogrammed cell death-1 (anti-PD-1) cancer immunotherapy. Diabet Med. 2017;34(Suppl 1):102.

162. Farrell C, Casasola R, Pearson E, Schofield C. Acute onset Type 1 diabetes precipitated by Pembrolizumab, an anti-PD-1 monoclonal antibody used as a treatment for melanoma. Diabetic Med. 2017;34(Suppl s1):1.

163. Gauci ML, Laly P, Vidal-Trecan T, Baroudjian B, Gottlieb J, Madjlessi-Ezra N, et al. Autoimmune diabetes induced by PD-1 inhibitor-retrospective analysis and pathogenesis: a case report and literature review. Cancer Immunol. 2017;66(11):1399-410.

164. Hickmott L, De La Pena H, Turner H, Ahmed F, Protheroe A, Grossman A, et al. Anti-PD-L1 atezolizumab-induced autoimmune diabetes: a case report and review of the literature. Target Oncol. 2017;12:235-41.

165. Ishikawa K, Shono-saito T, Yamate T, Kai Y, Sakai T, Shimizu F, et al. A case of fulminant type 1 diabetes mellitus, with a precipitous decrease in pancreatic volume, induced by nivolumab for malignant melanoma: analysis of HLA and CTLA-4 polymorphisms. EJD. 2017;27:2

166. Leonardi G, Oxnard G, Haas A, Lang J, Williams J, Awad M. Diabetic ketoacidosis as an immune-related adverse event from Pembrolizumab in non small cell lung cancer. J Immunother. 2017:40:3.

167. Matsumura K, Nagasawa K, Oshima Y, Kikuno S, Hayashi K, Nishimura A, et al. Aggravation of diabetes, and incompletely deficient insulin secretion in a case with type 1 diabetes-resistant human leukocyte antigen DRB1*15:02 treated with nivolumab. J Diabetes Invest. 2018;9:438-41. https://doi.org/10. 1111/jdi.12679 Epub 2017.

168. Mizab Mellha C, Perez M, Rey M, Garcia M. Fulminant type 1 diabetes mellitus associated with pembrolizumab. Endocrinología, Diabetes y Nutrición. 2017;64(5):2.

169. Munakata W, Ohashi K, Yamauchi N, Tobinai K. Fulminant type I diabetes mellitus associated with nivolumab in a patient with relapsed classical Hodgkin lymphoma. Int J Hematol. 2017;105:383-6.

170. Telo G, Carvalhal G, Cauduro G, Webber V, Barrios C, Fay A. Fulminant type 1 diabetes caused by dual immune checkpoint blockade in metastatic renal cell carcinoma. Ann Oncol. 2017;28:2.

171. Wright LA-C, Ramon RV, Batacchi Z, Hirsch IB. Progression to insulin dependence post-treatment with immune checkpoint inhibitors in preexisting type 2 diabetes. AACE Clin Case Rep. 2017;3:e153-e7.

172. Alzenaidi A, Dendy J, Rejjal L. Autoimmune diabetes presented with diabetic ketoacidosis induced by immunotherapy in an adult with melanoma. J La State Med Soc. 2017:169:49.

173. Godwin JL, Jaggi S, Sirisena I, Sharda P, Rao AD, Mehra R, et al. Nivolumab-induced autoimmune diabetes mellitus presenting as diabetic ketoacidosis in a patient with metastatic lung cancer. J Immunother Cancer. 2017;5:40.

174. Changizzadeh PN, Mukkamalla SKR, Armenio VA. Combined checkpoint inhibitor therapy causing diabetic ketoacidosis in metastatic melanoma. J Immunother Cancer. 2017:5:97.

175. Smith-Cohn M, Gill D, Voorhies B, Agarwal N, Garrido-Laguna I. Case report: pembrolizumab-induced type 1 diabetes in a patient with metastatic cholangiocarcinoma. Immunotherapy. 2017:9:8.

176. Kapke J, Shaheen Z, Kilari D, Knudson P, Wong S. Immune checkpoint inhibitor-associated type 1 diabetes mellitus: case series, review of the literature, and optimal management. Case Rep Oncol. 2017;10:897-909.

177. Kumagai R, Muramatsu A, Nakajima R, FUjii M, Kano K, Katakura Y, et al. Acute-onset type 1 diabetes mellitus caused by nivolumab in a patient with advanced pulmonary adenocarcinoma. J Diabetes Invest. 2017:8:798-9

178. Gambale E, Tinari C, Quinzil A, Cortellini A, Carella C, De Turst M. Nivolumab and diabetes mellitus: Safe administration in a patient with pancreatic metastases from melanoma. J Transl Med. 2017;15(Supplement 1):11

179. Lee JYM, Warshauer JT, Gilliam LK, Park-Segal J, Murphy EJ, Anderson MS. A case of acute severe insulin resistance and fulminant type 1 diabetes after immune checkpoint blockade cancer therapy. Endocr Rev. 2017:38(3):2004-17.

180. Nieves CA, Harlan DM, Thompson M, Suzuki S, Ali A. Autoimmune diabetes linked to nivolumab. Diabetes. 2017;66(Supplement 1):A353.

181. Reslan Z, Paull D. Pembrolizumab induced auto-immune diabetes and hepatitis. J Oncol Pharm Pract. 2017;23(Supplement 1):11.

182. Vodopivec DM, Piech MR, Treitter CG. Nivolumab induced autoimmune diabetes in a patient with metastatic renal cell carcinoma: a case report. Endocr Rev. 2017;38:2017-04.
183. Hao JB, Renno A, Imam S, Alfonso-Jaume M, Elnagar N, Jaume JC Development of type 1 diabetes after cancer immunotherapy. AACE Clin Case Rep. 2017;3:e242-5.

184. Villarreal J, Townes D, Vrablik M, Ro K. A case of drug-induced severe Endocrinopathies. What providers in the emergency department need to know. Adv Emerg Nurs J. 2018;40:16-20.

185. Capitao R, Bello C, Fonseca R, Saraiva C. New onset diabetes after Nivolumab treatment. BMJ Case Rep. 2018;2018:bcr-2017-22099 p1-3.

186. Trainer H, Hulse P, Higham CE, Trainer P, Lorigan P. Hyponatraemia secondary to nivolumab-induced primary adrenal failure. Endocrinol Diabetes Metab Case Rep. 2016:1-4. https://doi.org/10.1530/EDM16-0106.

187. Coskun NSS, Simsir IY, Göksel T. A case with a primary adrenal insufficiency secondary to nivolumab. Eur Respir J. 2016;48:PA4853.

188. Akarca FK, Can O, Yalcinli S, Altunci YA. Nivolumab, a new immunomodulatory drug, a new adverse effect; adrenal crisis. Turk J Emerg Med. 2017;17:157-9.

189. Zhao C, Tella SH, Del Rivero J, Kommalapati A, Ebenuwa I, Gulley J, et al. Anti-PD-L1 treatment induced central diabetes insipidus. J Clin Endocrinol Metab. 2018;103:365-9.

190. Mills TA, Orloff M, Domingo-Vidal M, Cotzia P, Bribe RC, Dragonova-Tacheva $\mathrm{R}$, et al. Parathyroid hormone-related peptide-linked hypercalcemia in a melanoma patient treated with Ipilimumab: hormone source and clinical and metabolic correlates. Semin Oncol. 2015;42:909-14.

191. Funasaka Y, Sato H, Chakrahorty AK, Obashi A, Chrouso GP, Ichihashi M. Expression of proopiomelanocortin, Corticotropin-releasing hormone $(\mathrm{CRH})$, and $\mathrm{CRH}$ receptor in melanoma cells, nevus cells, and Normal human melanocytes. J Investig Dermatol Symp Proc. 1999;4:105-9.

192. Schteingart DE, Llyod RV, Akil H, et al. Cushing's syndrome secondary to ectopic Corticotropin-releasing hormone-Adrenocorticotropin secretion. J Clin Endo Metab. 1986;63:770-5.

193. Faje AT, Lawrence D, Flaherty K, Freedman C, Fadden R, Rubin K, et al. Highdose glucocorticoids for the treatment of Ipilimumab-induced hypophysitiss is associated with reduced survival in patients with melanoma. Cancer. 2018;124:3706-14

194. Ni J, Qiu LJ, Zhang M, Wen PF, Ye XR, Liang Y, et al. CTLA-4 CT60 (rs3087243) polymorphism and autoimmune thyroid diseases susceptibility: a comprehensive meta-analysis. J Endocr Res. 2014:39:180-8.

195. Cukier P, Santini FC, Scaranti M, Hoff AO. Endocrine side effects of cancer immunotherapy. Endocr Relat Cancer. 2017;24:T331-47.

196. Postow MA, Sidlow R, Hellmann MD. Immune-related adverse events associated with immune checkpoint blockade. N Engl J Med. 2018;378:158-68.

197. Byun D, et al. Cancer immunotherapy_immune checkpoint blockade and associated endocrinopathies. Nat Rev Endocrinol. 2017;13:195-207.

198. Abdel-Rahman O, El Halawani H, Fouad M. Risk of endocrine complications in cancer patients treated with immune checkpoint inhibitors: a metaanalysis. Future Oncol. 2016;12:413-25.

199. Barroso-Sousa R, Barry WT, Garrido-Castro AC, Hodi S, Min L, Krop IE, et al. Incidence of endocrine dysfunction following the use of different immune checkpoint inhibitor regimens a systematic review and meta-analysis. JAMA Oncology. 2018:4:173-82.

200. Imagawa A, Hanafusa T, Swsts T, Ikegami H, Uchigata $Y$, et al. Report of the Committee of the Japan Diabetes Society on the research of fulminant and acute-onset type 1 diabetes mellitus: new diagnostic criteria of fulminant type 1 diabetes mellitus (2012). J Diabetes Invest. 2012;3:536-9.

201. Stamatouli AM, Quandt Z, Perdigoto AL, Clark PL, Kluger H, Weiss SA, et al. Collateral damage: insulin-dependent diabetes induced with checkpoint inhibitors. Diabetes. 2018;67:1471-80.

202. Chen TW, Razak AR, Bedard PL, Siu LL, Hansen AR. Systematic review of immune-related adverse events reporting in clinical trials of immune checkpoint inhibitors. Ann Oncol. 2015;26:1824-9.

203. https://medicine.uiowa.edu/internalmedicine/education/master-clinicianprogram/students/clinical-and-diagnostic-reasoning. Accessed 10 Aug 2018

204. Illouz F, Briet C, Cloix L, Le Corre Y, Baize N, Urban T, et al. Endocrine toxicity of immune checkpoint inhibitors: essential crosstalk between endocrinologists and oncologists. Cancer Medicine. 2017;6:1923-9.

205. Rossi E, Sgambato A, Chiara D, Casaluce F, Losanno T, Sacco PC, et al. Endocrinopathies induced by immune-checkpoint inhibitors in advanced non-small cell lung cancer. Expert Rev Clin Pharmacol. 2016;9:419-28.

206. Barroso-Sousa R, Ott PA, Hodi S, Kaiser UB, Tolaney SM, Min L. Endocrine dysfunction induced by immune checkpoint inhibitors: practical recommendations for diagnosis and clinical management. Cancer. 2018;124: $1111-21$. 
207. Haanen JBAG, Carbonnel F, Robert C, Kerr KM, Peters S, Larkin K, et al. Management of toxicities from immunotherapy: ESMO Clinical Practice Guidelines for diagnosis, treatment and follow-up. Ann Oncol. 2017; 28(Supplement 4):iv119-42.

208. Brahmer JR, Lacchetti C, Schneider BJ, Atkins MB, Brassil KJ, Caterino JM, et al. Management of Immune-Related Adverse Events in patients treated with checkpoint inhibitor therapy: American Society of Clinical Oncology clinical practice guideline. J Clin Oncol. 2018;36:1714-1768.

209. Higham CE, Olsson-Brown A, Carroll P, Cooksley T, Larkin J, Lorigan P, et al. Acute management of the endocrine complications of checkpoint inhibitor therapy. Endocr Connections. 2018;7:G1-7.

Ready to submit your research? Choose BMC and benefit from:

- fast, convenient online submission

- thorough peer review by experienced researchers in your field

- rapid publication on acceptance

- support for research data, including large and complex data types

- gold Open Access which fosters wider collaboration and increased citations

- maximum visibility for your research: over $100 \mathrm{M}$ website views per year

At BMC, research is always in progress.

Learn more biomedcentral.com/submissions 